Portland State University

PDXScholar

7-29-1994

\title{
Youth's Perceptions of Social and Cultural Dimensions of Drug Use
}

Brett Joseph Casper

Portland State University

Follow this and additional works at: https://pdxscholar.library.pdx.edu/open_access_etds

Part of the Psychology Commons

Let us know how access to this document benefits you.

\section{Recommended Citation}

Casper, Brett Joseph, "Youth's Perceptions of Social and Cultural Dimensions of Drug Use" (1994). Dissertations and Theses. Paper 4720.

https://doi.org/10.15760/etd.6604

This Thesis is brought to you for free and open access. It has been accepted for inclusion in Dissertations and Theses by an authorized administrator of PDXScholar. Please contact us if we can make this document more accessible: pdxscholar@pdx.edu. 
THESIS APPROVAL

The abstract and thesis of Brett Joseph Casper for the Master of Science in Psychology were presented July 29, 1994 and accepted by the thesis committee and the department.

COMMITTEE APPROVALS:

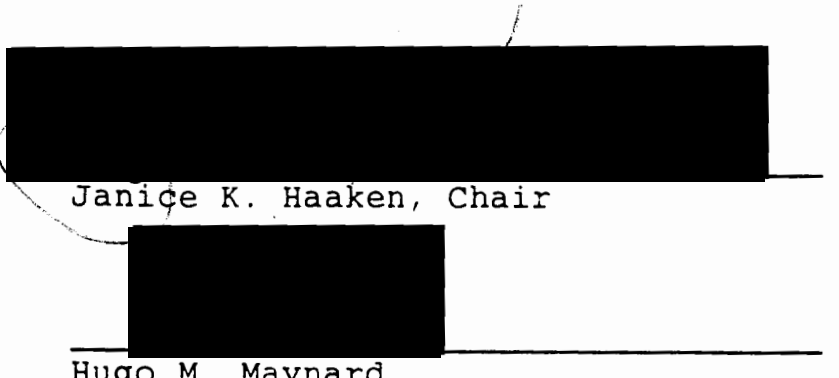

Hugo M. Maynard

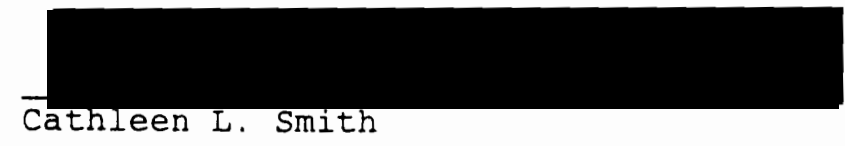

DEPARTMENT APPROVAL:

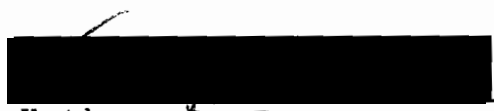

Kathryn A. Farr Representative of the office of Graduate Studies

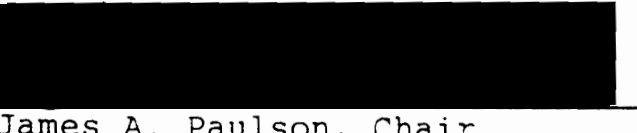

Departillent of Fsychology

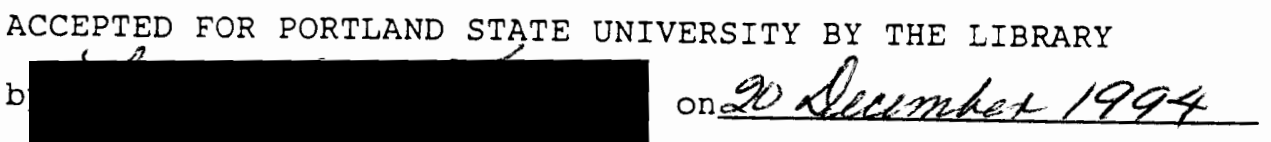




\begin{abstract}
An abstract of the thesis of Brett Joseph Casper for the Master of Science in Psychology presented July 29, 1994.

Title: Youth's Perceptions of Social and Cultural Dimensions of Drug Use.
\end{abstract}

This study explores youth's perceptions and understanding of the social phenomenon of drugs in our society. Sixty-four students (32 fourth graders and 32 eleventh graders), selected from schools in the Portland Public School District participated individually in a one hour interview where they responded to open ended questions that probed for their perceptions of drug use. Participants were also asked to describe their feelings regarding anti-drug messages they view in the media and their comments regarding the "Just Say NO" program. The tape-recorded interviews were transcribed and half were used to develop a code that captured recurring themes in the data. Using the code book, five trained individuals coded the 64 transcripts. Reliability, assessed by computing Cohen's Kappa on half the interviews, ranged from .62 to .75, with an average reliability of .69 .

Seventeen themes derived from the content analysis were discussed which confirm the dramatic impact the peer group has on drug use as well as demonstrate age differences associated with perceptions of anti-drug messages. One hundred percent of the participants noted that there are peer influences promoting drug use. Eleventh graders were more likely 
than fourth graders to note that drugs are used as a means to escape, overcome constraints or for pleasurable stimulation. Fourth graders were more positive in their responses to the anti-drug commercials and the "Just Say No" campaign.

This research provides information regarding the perceptions of young people that can potentially broaden the dialogue of program planners as well as increase the effectiveness of anti-drug programs and messages. 
YOUTH'S PERCEPTIONS OF SOCIAL AND CULTURAL DIMENSIONS OF DRUG USE

BY

BRETT JOSEPH CASPER

\begin{abstract}
A thesis submitted in partial fulfillment of the requirements for the degree of
\end{abstract}

\title{
MASTER OF SCIENCE
}

IN

PSYCHOLOGY

Portland State University

1994 


\section{ACKNOWLEDGMENTS}

I would like to acknowledge and thank the many people that provided help and support making the completion of this project possible:

To my advisor and committee chair Dr. Janice Haaken whose

continued support, encouragement and knowledge were greatly appreciated;

and to my committee members Dr. Cathleen L. Smith, Dr. Hugo M. Maynard and Dr. Kathryn A. Farr for their expertise and guidance.

To the faculty at Portland State University for their instruction and knowledge.

To my friend and colleague Nancy Thayer for generous support and encouragement.

To Janet Gillman, Linda Brownlee, Erica Storm, Shaun Bacon, Ron Yoder and Carol Holt for their efforts in interviewing, coding and transcribing.

To The Portland Public Schools for supporting and partially funding the project.

Finally, I want to express my love and appreciation to my wife and family for their support and encouragement to the end. 


\section{TABLE OF CONTENTS}

PAGE

ACKNOWLEDGEMENTS

CHAPTER ONE INTRODUCTION 1

Psychosocial Theories of Etiology 3

Media Influences 13

The "Just Say NO" Program 17

CHAPTER TWO METHOD 19

Respondents 19

Interviews 20

$\begin{array}{ll}\text { Coding } & 21\end{array}$

$\begin{array}{lll}\text { CHAPTER THREE RESULTS } & 24\end{array}$

Reasons for Drug Use 25

Gender Differences 31

SES Differences 33

Media Influences $\quad 35$

"Just SaY NO" Responses 40

$\begin{array}{lll}\text { CHAPTER FOUR } & 45\end{array}$

$\begin{array}{ll}\text { Limitations of This study } & 57\end{array}$

Future Research 58

$\begin{array}{lll}\text { CHAPTER FIVE SUMMARY AND CONCLUSION } & 60\end{array}$

$\begin{array}{ll}\text { BIBLIOGRAPHY } & 63\end{array}$

APPENDICES

$\begin{array}{ll}\text { A Interview Schedule } & 66\end{array}$

B Consent Form $\quad 71$

$\begin{array}{ll}\text { C Code Book } & 77\end{array}$

D Theme Occurrences $\quad 85$

E Kappa Totals $\quad 86$ 
CHAPTER ONE

\author{
INTRODUCTION
}

In the past three decades a great deal of concern has been expressed over the increased drug-taking behaviors exhibited by youth. There has been a renewed campaign against the use and abuse of drugs that culminated in the "war on drugs" in the 1980s. Researchers have sought to develop programs that not only inform youth of the dangers of drug, tobacco and alcohol use but also help young people develop strategies to avert use.

Although there has been a general decline in drug use since the 1970s, it has been difficult for researchers to associate this decline with any particular method or program. A great deal of money and effort has been invested in these programs; unfortunately, evaluations have demonstrated that many of these programs need further development in that they are often ineffectual in reducing arug and alcohol use (Tobler, 1986; Moskowitz, 1989). Current strategies have incorporated television as well as other mass media sources to promote anti-drug messages.

A number of researchers have sought to explain the failures or limitations of anti-drug programs. One of the primary explanations is that increased knowledge does not always lead to a change in attitude or behavior. In some cases increased knowledge has eventuated in an increase in drug use or experimentation (Hopkins, Mauss, Kearney \& 
Weisheit, 1988; Moskowitz, 1989). Some researchers have suggested that unless our society as a whole changes and provides youth with different role models or social rewards, drug abuse will continue to be an intractable problem (Newcomb, 1989). Children often face the overwhelming task of sorting out the many images and messages related to licit as well as illicit drugs. It may be that only programs based on sound psychological principles which take into account the numerous factors influencing behavior will produce the desired results.

This study is an attempt to discover and more fully understand some of the underlying variables that are associated with young people's understanding of the social phenomenon of drugs in our society. Since young people typically spend many hours watching television and following the lives of celebrities it becomes increasingly important to understand how television negatively influences them as well as the potentially positive ways it might affect them. Anti-drug commercials in conjunction with educational programs and the "Just say No" campaign are a few of the current programs being used. In gaining a better understanding of youth's conceptions of motivations for use and of societal influences, we are better able to provide a solid groundwork from which new and more effective anti-drug programs can be constructed. Previous studies have relied largely on forced choice questionnaires in which the researcher defines the range of answers. In this study, participants are given open-ended questions which allow them to frame their own responses and describe more fully their perceptions of the relative strength of the many forces that contribute to the formation of thoughts and behaviors relative to drug use. 
The data presented in the present inquiry were collected as part of a larger study which included a section focusing on moral reasoning and the way young persons conceptualize dilemmas associated with drug use. This part of that larger study focuses on the perceptions of young people regarding social influences such as television, the media and their friends as they affect adolescents' involvement in drug use.

\section{REVIEW OF THE LITERATURE}

\section{Psychosocial Theories of Etiology}

Psychosocial approaches to adolescent drug use examine the effects that drug use by significant others has on both the initiation into experimentation and the continuing use of drugs. These theories describe the circumstances in which both the opportunity and motivation for drug use can occur. In illustrating the importance of social factors, Oetting and Beauvis (1987) note that for many youth the social effects of drug use are often more reinforcing than the psychological or pharmacological effects of drugs. The peer group has been identified as the primary influence for middle adolescent youth who are exposed to drug involvement, while during later adolescence one or two close friends who may be using drugs become more important.

Research has demonstrated that nearly all drug experimentation and use originates in the pre-adolescent or adolescent years loetting, 1987; Glynn 1981). This is primarily due to the increase in frequency or intensity of peer interaction which is typically accompanied by conformity to peer behaviors. During this period parental control and 
influence may lessen as the peer group plays a more pronounced role. Pisano and Rooney (1988) noted that there are significant increases in susceptibility to peer influences beginning in the fourth grade and continuing through adolescence. They indicated that there may be a transition period in which the power of peer pressure increases to equal and then exceeds parental and adult influence.

Sutherland and Cressey (1970) assert that one crucial factor in the promotion of delinquent behavior within peer groups is the availability of delinquent role models. Moreover, Detting and Beauvais (1987) state that

peers initiate the youth into drugs. Peers help provide the drugs. Peers talk with each other about drugs and model drug using behaviors for each other and in so doing shape attitudes about drugs and drug using behaviors (p. 137).

They also note that even the use of a drug in a solitary situation is a function of the attitudes and beliefs shared by the peer group. Kandel (1980) asserts that even after controlling for other major factors, peer-related factors are consistently the strongest predictors of subsequent alcohol and marijuana use.

\section{Family Influences}

While the documentation of peer influence on drug behavior is substantial, some researchers have shown that conceptions of peer groups are subject to change during the adolescence years. While it is true that during the adolescent years the peer group plays a significant role, this influence is still mediated by the youth's primary source of 
socialization - the family. Researchers have shown that the influence of family and peers is interactional and independent. In relation to drug use, Glynn (1981) further notes that drug behavior at any point is not wholly influenced by either family or peers. In describing the relative influence of peers and parents, Berndt (1979) showed that conformity to peers in anti-social behavior begins to increase between the third and ninth grades, remains steady during preadolescent years, and then begins to decline in late adolescence.

Biddle, Bank and Marlin (1980) further showed younger respondents as being mostly affected by parental norms and less influenced by the norms established by their friends. However, respondents in their mid teens were most affected by reported peer pressures and least affected by attributed parental norms. By the tenth or eleventh grades the parent-peer relationship enters into another phase with the adolescent accepting more parental guidance and conventional standards.

Both studies provide evidence for the assertion that there are developmental changes in conformity to parents and peers which tend to form a U shaped age trend. That is, conformity to parental values is greatest during early childhood, shows decreasing influence during early adolescence, and again is prevalent during later adolescence. The results also provide some indication of the changing and often conflicting feelings youth experience as they interact with parents and peers.

One explanation for a change in attitude is that older adolescents are more mature cognitively and can effectively synthesize both parental messages as well as information they receive through other social 
experiences. It may be that they are better able to hear, understand and think about messages given to them by their parents and other family members.

Pharmacological or Experiential Reasons

Another approach explaining motivation for drug use focuses on the rewarding effects of mind-altering substances or the pleasure of experimentation. Curiosity, relaxation and recreation are some of the frequently cited motives for drug consumption and have been consistently endorsed as reasons for use in a study by Pascale and Evans (1993) which covered a span of twelve years with five major data sets. For each cohort survey, there was strong agreement in how the genders rated their reasons for taking drugs. The most stable areas of endorsement appear to be in peer influences, i.e., "everyone does it" and in attempts to achieve relaxation or to relieve tension. Curiosity is also frequently reported as a reason for using drugs and accounts for nearly half the instances of self-reported drug use. Male cohorts in this study demonstrate a significant linear increase across data collection points in the area of recreation or for fun as a reason for the use of drugs while females have a significant linear increase in the category of rebellion against authority as a reason for use. 


\section{PERCEPTIONS OF DRUG USE AMONG CHILDREN}

AND ADOLESCENTS

Although considerable literature has developed on drug use and youth, there is relatively little research on adolescents' perceptions of the relationship between peer pressure and drug use. This study is a response to this gap in knowledge of how young persons understand social phenomena associated with drug behavior.

Pascale and Evans (1993) in their work with eleventh graders record a positive trend in perceived harmfulness associated with the use of almost all drugs. Historical lows in their data were observed in the 1989 and 1992 data across nearly all drug categories, especially with respect to marijuana. Here the data show not only the lowest reported usage in five cohorts but also a thirty-five percent increase from 1977 to 1993 in the category of perceived harmfulness of marijuana.

Bachman, Johnston, and O'Mally (1988) also argue that changes in perceptions have been leading to changes in the use of some substances. They note that in 1980 a steady decline in drug use, specifically marijuana use, was occurring among most age categories and that by 1986 levels of use had dropped below the relatively high 1975 and 1979 consumption rates. They generated two possible explanations for this decreasing trend. The first one proposes that young people have become more conservative and less "trouble prone." The second interpretation states that there have been specific changes in the way adolescents view marijuana and the risks associated with its use. After controlling for 
lifestyle factors the authors found no support for the notion that there has been an overall conservative shift that can account for decreased marijuana use. Their data lead them to believe that both perceived risks and personal disapproval of marijuana use, especially regular use, have risen sharply since 1975 .

The downward trend in some of these areas may indicate that young persons are becoming more aware of the dangers involved in drug use. However, Pascale and Evans (1993) note that prevention methods are still in need of improvement. They encourage improvement of existing programs as well as continued development of new programs during this time when there is public interest and support for anti-drug programs. They further caution that there is danger in assuming that this downward trend in usage of alcohol and drugs will continue into the future as young people are taught more of the health risks. Their data demonstrating already high levels of perceived harmfulness in the nineties may reflect a ceiling effect. In other words, most young persons are aware that drug use is dangerous and continued reiteration of this message is not likely to produce any further effects.

In a related study, Brown, Clasen and Eicher (1986) analyzed data related to drug use and other behaviors collected from three areas: conformity dispositions, perceived peer pressure and self reported behavior. Perceived peer pressures toward involvement in pro-social behaviors were often viewed as positive in nature while there was more ambivalence toward perceived misconduct pressures, with some respondents indicating they felt both positive and negative pressure from friends. Participants drawn from the sixth to the twelfth grades in this study 
demonstrated more willingness to follow peers in behaviors that were neutral or pro-social than less socially endorsed behaviors such as drug/alcohol use, sexual intercourse and minor delinquent behavior. According to Brown et al. (1986), students perceive more pressure toward deviance with age and boys are more likely than girls to follow peers into antisocial behaviors. Their conclusions suggest that perceived peer pressure and peer conformity dispositions accounted for more variance in self-reported misconduct than did actual peer involvement. The researchers comment on the bi-directional nature of peer pressure suggests that there are potentially pro-social influences of peers even in antisocial behavioral domains. This may provide some indication of the conflicting influences that adolescents encounter in different situations.

Pruitt, Kingery, Mirzaee, Heuberger and Hurley (1991) described three items which most closely predicted concurrent drug use: 1) number of friends perceived to smoke marijuana, 2) number of friends who use cocaine, 3) number of friends perceived to take amphetamines. Their findings indicate that adolescents' perceptions of their friends' illegal drug use were more important than any information they received or their own attitudes. They noted that those students at highest risk had more friends who use drugs and concurrently receive more information from their friends about drugs. At the same time participants reporting the lowest use among friends and receiving a lesser amount of information from friends were at a lower risk for illegal drug use. Reid (1987) corroborated this result by showing that drug use was heaviest among older students who demonstrate favorable attitudes 
regarding personal drug use and who have peers that have used drugs in the past or that are still using. As suspected, their beliefs about the personal consequences of drug use were more positive and problem behaviors in general were more prevalent.

\section{Racial Differences}

Racial differences relative to drug use and abuse in the last two decades have declined (Blount and Dembo, 1984). Research has shown that the effect of race or ethnicity is somewhat elusive. Frequently racial and ethnic differences are confounded with differences due to class, income and education and are thereby difficult to estimate with precision. Some research findings have shown only minimal differences between the races in general substance abuse, but have noted specific trends.

Hareford (1978) has reported that black youth typically drink less than white youth. When black youth do drink, it is usually with their parents and they are less likely to drink with peers (Higgins, Albrecht and Albrecht 1977). Estimates on marijuana and cocaine consumption have indicated that use for white youths is higher although the differences are usually small (Higgins et al, 1977).

Various other authors, however, have proposed that there is differential use of various substances by ethnic groups and have tried to explain why these differences might occur. Newcomb and Bentler (1985) proposed that differences may be the result of exposure to different peer or adult role models. As a second component, they assessed varying vulnerabilities of ethnic groups to modeled behavior. 
Their results indicated that white and hispanic groups were the most receptive to modeled drug use behavior and concurrently reported the highest frequency of use for all drugs. Black participants reported only moderate levels of drug use while demonstrating the least vulnerability or compliance to peer and adult models. They go on to note that the lower levels of substance use by blacks may due to their invulnerability to the influence of peer models. Asians tended to report the lowest use of drugs and to have relatively few peer or adult models of drug use.

\section{Gender Differences}

Recent research into gender differences has shown a similar lessening of the gap between the sexes with regard to drug, alcohol and tobacco use. The clear trend in the past has shown that males were more likely than females to use drugs, especially illicit drugs and alcohol. Males were much more likely to drink heavily, meaning five or more drinks (beer) in a row, than are females (Johnston \& O'Malley, 1986). Young men have often been thought of as having personality characteristics which describe them as being more rebellious, inclined to take risks and in general being less religious (Herzog, 1987).

However, it now appears that the "double standard" in substance use may be diminishing. Traditional norms are in transition as changes in sex roles tend to increase women's exposure to alcohol and other substances making their use more permissible. In their reported frequencies of fourteen categories of various substances, Pacale and Evans (1993) showed a general decrease in use by both genders from their 
1986 data. Coffee is the only substances showing an increase in use by both males and females while females record an increase in alcohol and hallucinogen use. Marijuana was the most commonly used illegal substance and for the first time in five cohorts (1977-1989) had a higher usage for females than males.

There continue to be gender differences in the age of initial experimentation. On average, females are initiated into alcohol and other drug use about a half year later than males (Pascale \& Evans, 1993).

\section{Socio-economic status}

There are frequently misconceptions regarding the populations that are most often seen as using drugs. Often those of certain economic status, race or gender are represented in the media as frequent users and are thereby most hard hit with community control measures. It is interesting to note the statistics reported in the literature and compare it with the perceptions of young people in this study. Racial and ethnic groups are often represented disproportionately in lower socio-economic groups. In some cases those of lower income are also frequently categorized in the "at risk" populations that may require special interventions. Haaken and Bowlden (1991) note that although consumption levels of alcohol and other drugs have been greater among the upper class, the ideological targets of the anti-drug campaign have typically been people of color. They further note that "the drug war and its effects on youth is a different reality in the poor and minority 
communities, many of which have become mini-police states through the stepping up of law enforcement" (p. 21).

\section{MEDIA INFLUENCES}

Communication through the mass media has become a primary component of many health promotion strategies designed to alter certain non-normative behaviors. The powerful influence of the media makes them an obvious choice for prevention programs. The mass media not only influence individuals and their behaviors, but they can impact the values of the community as well.

The role of the media (TV, newspapers and magazines) as a factor contributing to the nation's substance use dilemma cannot be overlooked. Movie and television stars are seen nightly drinking, smoking and using other substances by millions of viewers. The effect of these models is a relevant concern, especially in relation to younger viewers. From an early age, children tend to watch a great deal of television and frequently make heroes of their favorite characters.

Defoe, Breed and Breed (1983) examined exposure rates to alcohol during prime time television shows. Their data indicate that viewers are exposed to more than eight "alcohol acts" per hour and that the preferred beverage consumed on these programs contained some alcohol. Alcohol acts were not limited to ingestion of alcohol, but included the portrayal of the character being "prepared" to drink, having ordered, accepted or prepared a drink. Defoe and colleagues express concern that 
those drinking are many times not shown to receive punishment or some of the other negative consequences associated with drinking.

Mirzaee, Kingery and Pruitt (1991) indicated that eighth and tenth graders perceive TV to be "a major source of drug information for all categories of drugs." Subjects were asked to note the amount of information they received from sources including: family, friends, church, siblings, teachers, magazines, TV and others. They conclude that between 47 and 66 percent of the students indicated TV as the source that is providing them with much or a great amount of information about the different categories of drugs" (p. 98). Newspapers and magazines were also mentioned as a primary source of information to these young people. Eighth graders reported having received more information from the media and public sources while tenth graders reported receiving a greater amount of information from their friends. Males also reported receiving significantly more information in general regarding most substances than did females.

To offset this barrage of media influence, Oie and Baldwin (1992) observe that short, easily comprehended anti-smoking spots portraying popular cartoon characters, children's television stars and well known sports figures might be used to convey anti-smoking and antidrug use messages. They note that cartoons and other children's shows that include health messages promoting safety could be adapted to convey anti-smoking messages in an interesting and comprehensible manner. Television has the advantage of not only affecting the viewer, but the entire peer group as well. Moreover, using television as a back-up to school prevention programs and parent's ongoing education efforts might 
prove a useful method for decreasing alcohol and other drug use. In this way sources of influences may function additively, confirming and supporting other programs in the desired direction.

\section{Commercials and Advertising}

Current mass media campaigns use a number of commercials along with warnings in magazines and newspapers to encourage young people not to use drugs. Most of the messages delivered in these commercials and posters portray the negative consequences of drug abuse. Some demonstrate the negative effects of parental modeling, while others use a more allegorical approach, e.g., "your brain on drugs" being shown as an egg frying. Many have attempted to shock young people with melodramatic portrayals of the consequences of uncontrolled use rather than merely providing information.

Some researchers have demonstrated that media campaigns, including paid programming, do increase the targeted audience's exposure to antisubstance use messages (Erickson et al., 1990). Flynn et al. (1992) generated more negative views from students toward smoking when combining educational channels with a mass media television component. They attempted to promote a more negative view of smoking while teaching cessation skills and making students more aware of current marketing techniques used by tobacco companies. The first group was exposed to only the educational components while the second group saw a combination of educational, radio and television spots that reinforced the previous instructions. Their data indicate that the group exposed to the combined educational and media components demonstrated a consistent 
trend toward less smoking than the educational component only group. They conclude that carefully targeted mass media programs combined with school educational programs can have an effect by discouraging the adoption of smoking.

The picture presented by Collins and Cellucci (1991) was not nearly as encouraging. They recommend that media messages should be combined with other communication activities such as TV segments and classroom curriculum. Their data indicate that while students' knowledge was affected by an alcohol education program with a media component, there were no measurable long-term effects on attitudes or behavior. Collins and Cellucci (1991) observe that as long as social norms continue to favor the use of some substances, especially alcohol, media announcements will have little effect on attitudes.

The media have become a primary transmitter of health information through news and other features as well as through character portrayals in entertainment. Because of the far-reaching effects of the media, Arkin (1990) notes that the public health community has a responsibility to identify how the media influence the public and promote those methods that demonstrate effective results.

One of the current emphases in the media is to sharpen public awareness by concentrating on public policy to serve the public interest. This involves changing the entire social context of substance use in America rather than the behavior of individuals (Erickson, 1990). In essence this strategy endeavors to control smoking and other substance use by shifting emphasis from individual behavior to changing the societal view of these behaviors. Erickson predicts that as larger 
societal attitudes toward substance abuse become more negative, personal behaviors and attitudes will follow.

The "Just Say No" Campaign

"Just Say No" is a slogan young people have been encouraged to adopt in their fight against drugs. Parents, teachers and many celebrities have taken part in this national program to deter substance use by young people. It was felt that if young people could avoid getting started then they would not get involved in long term abusive patterns.

The main criticism of the program is that it is simplistic and incomplete (Kelly, 1991). It fails to promote skills that lead to a healthy lifestyle. The reasons for drug use and addiction are varied and complex and often override efforts to "Just say No". Kelly (1991) further notes that there is also an economic factor. As long as material goods that are valued by society can be purchased with money obtained through dealing drugs and as long as drug dealers have more money than prevention programs, simple slogans will not suffice.

The use of celebrities, sports figures and politicians in the "Just Say NO" campaign has met with limited success. While many of these famous individuals have worked hard to share experiences and promote the "Just Say No" program, the longevity of the motivation provided by their speeches and testimonials is limited. Without comprehensive follow-up programs to strengthen ideals, many students return to "pre-speech" levels within a few days (Kelly, 1991). Encouragement expressed by an important authority figure is most 
effective when there is a good relationship between the sender and the receiver. In most cases the formation of this type of relationship is impossible and therefore the impact of his/her message is soon forgotten.

For the past three decades there has been a fair amount of research exploring both the rationale for drug use among youth as well as the extent to which various types of drugs are used. There is very little research focusing on youth and their perceptions of events and social phenomena associated with drug use.

The present study allows the participants to provide a more phenomenological view of influences that affect both their views and behaviors which might fill in gaps left by other methods. Moreover, allowing young people to become involved in the dialogue will broaden our understanding of their experiences and feelings when dealing with these issues 
CHAPTER TWO

METHOD

\section{Subjects}

Sixteen males and sixteen females from the fourth $(\mathrm{n}=32)$ and eleventh $(n=32)$ grades were selected from four schools in the Portland Public School District. Two Northeast Portland high schools (Grant and Jefferson) and two elementary schools (Irvington and Sabin) were selected due to their representation of comparable ethnic and socioeconomic groups. The families in the surrounding areas of these schools have a range of lower to middle class incomes. In order to reduce the possibility of school effects due to location, schools close in proximity were used to obtain the pool of subjects. The age range for the fourth graders was $8-9$ and for the eleventh graders it was 1617. The total sample was comprised of equal groups according to ethnicity (African American and Caucasian) and gender.

The principal from each school selected three classrooms based on accessibility and representation of students from which the participants were to be drawn. Pupils in these classrooms were presented with an overview of the study by a graduate student and invited to participate. Volunteers were sent home with a form (see Appendix B for the consent form) requesting consent from the student and parents along with a letter from the school principal supporting the study and inviting students to participate. 
students were informed of the complete confidentiality of their responses and assured that refusal to participate would not affect their school standing in any way.

\section{Instruments}

Data for the study were collected from individual interviews based on an interview schedule (see Appendix A for the interview schedule). Questions developed by the research team were designed to probe respondents for their conceptions and understanding of issues related to drugs in the media and in their schools. In particular, students were asked to describe their feelings regarding the anti-drug commercials they view on television and the "Just Say NO" program. Participants were also asked why they thought both older and younger people start using drugs and what role attracting and maintaining friends plays in that process.

A pilot study was completed by the research team to evaluate the interview schedule. Four primary school-aged and four high school-aged students were selected and participated in the pilot interviews. Using the transcribed interviews as a guide the interview schedule was further refined.

\section{Interviewers}

The interview team was comprised of two graduate students and one senior undergraduate student at Portland State University. Training of interviewers occurred prior to and throughout the pilot study, including discussion of open-ended interviewing techniques and practice through 
role playing. The pilot interviews permitted practice and further refinement of interviewing skills with four fourth and four eleventh grade participants. Each of the three interviewers was assigned approximately the same number of subjects at each of the schools and in each of the grades.

\section{Procedure}

Each participant was interviewed at his/her school by one of three trained graduate students during a prearranged release time from classes. Interviews were conducted in private rooms on site at the school. The length of each interview ranged from 50 minutes to 70 minutes.

At the onset of each interview students were thanked for their participation, informed of the procedure of the interview and told that they may end the interview at any time. All questions, responses and comments were audio taped for later transcription and analysis. Each tape was assigned a number and secured in a location to which only the research team had access.

\section{Interview coding}

Following the transcription of the interviews, a code book was developed using approximately half of the interviews as a guide to identify emerging themes of theoretical interest (see Appendix $C$ for the Code Book). The code book contained an index of major headings, the specific themes or codes, the complete definition of each code as well as demonstrative examples of the usage of the code. 
Following the development of the code book, all raters were trained by Janice Haaken, PhD, of Portland State University. The coding team was comprised of two graduate students and four undergraduate students. Coders were trained to recognize themes and make independent judgments in each response unit (a response unit was defined as a verbalization by the respondent uninterrupted by the interviewer). The use of each code was limited to one per response unit with codes being mutually exclusive. Following the actual coding of five transcripts, additional training sessions were held to insure proper usage and understanding of the code.

Following the completion of the coding, inter-coder reliability was assessed using Cohen's Kappa (Ferguson 1981). This involved selecting randomly three different sets of twelve transcripts (total 36) and computing the Kappas for each interview by section. This was accomplished by isolating the same section from each transcript (defined by topic), calculating the number of codes in that section and then combining the total number of codes assigned to calculate Kappa. In this way a more accurate assessment of the inter-coder reliability for each topic was established. Interater reliability (Cohen's Kappa) for the determination of each of the themes ranged from .62 tp .75 with an average of .69 .

\section{Data Analysis}

The Ethmograph software package was used to isolate and record the occurrence of each of the codes. The frequency of each code was recorded and the percentages were then calculated. 
On the basis of the factors of age, ethnicity and gender, Chi Square tests were conducted to test for independence of each of the themes. 
CHAPTER THREE

RESULTS

Transcriptions from the interviews with 32 fourth graders and 32 eleventh graders were coded for the appearance of themes. The code book included 44 codes of theoretical interest that were generated by the research team. Interrater reliability (Cohen's Kappa) for the determination of each of the themes ranged from .66 to .75 across six sections or categories, with an average of .69 (see Appendix E). The Ethogsaph software program aided in reducing data by recording the location and line numbers of each theme for later retrieval.

Due to the large quantity of material, tests of significance were performed on 30 of the themes following which 17 were selected for development and discussion (see Appendix D). These themes were selected on the basis of their theoretical relevance to the aims of the study. (The code sets in the area of parental relationships and perceptions of governmental involvement in the drug war were not used and will be more fully developed in future papers. The codes related to perceptions of the media were not used due to the below criterion Kappa results.) The themes selected dealing with issues related to peer influences and the media (television commercials), and the "Just Say No" program provided the information most closely related to the interests and direction of the researchers and were therefore most fully developed. 
The Chi Square statistic was used to determine the association in the occurrence of each of the themes by gender, race (ethnicity) and age (9-10 year old students, fourth grade and 16-17 year old students, eleventh grade). Of the 30 tests of significance for each variable, 3 were significant by race (ethnicity), 5 were significant by gender and 17 were significant by grade (see Appendix D).

\section{REASONS FOR DRUG USE}

There were many reasons provided by young people for both beginning and continuing the use of drugs and other substances. This study primarily investigated perceptions of drug use and did not inquire into personal experiences related to the drug use of the participant. of primary interest was participants' perceptions of why young people use drugs. Young persons clearly indicate that the peer group is a primary facilitator of drug use. The theme which indicates that there is a strong desire for peer conformity or identity from the group and a need for approval from peers (peer-gr) occurred in all the transcripts $(100 \%)$. Many participants commented on how strongly the peer group promotes drug use.

Well, when you are doing drugs, you make friends better, you know, they think drugs are cool. And they think they will lose a friend if they don't do it. And they don't care, probably don't care about their lungs or their health. (pl, grade 4, female; pl indicates participant number one)

Many young people feel they must participate in these activities or be left out of "the crowd".

Yeah, they do it because it's cool, because their friends do it. And they think if their friends do it, they should do it. (p4, grade 4, female) 
Yeah, yeah, definitely. I think if their friends say it feels good and it's really cool. Sure they will. (p45, grade 11, female)

The next most frequently reported reason in this study was to escape from problems, i.e., pressures or stress from family, friends, boredom (depression, passivity) or problems imposed by external demands (PHARM-ESC). Although mentioned by seventy-five percent of the fourth graders, it is even more salient for the eleventh graders, where $100 \%$ made reference to the use of substances as a vehicle to escape from pressures, $x^{2}(1, \underline{n}=32)=9.14, \underline{p}<.01$.

To escape from life. Hey, I don't want to do this. This will make me feel good for a little bit, then maybe after it's done, then I can think clearly I'll be over, I'll have my good time, and then I can really get back to work or something. Like taking a break out of life, they'il take a big break, maybe. Then you might take a big break and never come back. (p27, grade 4, male)

Some people take drugs 'cause they feel depressed, some people take drugs to try to help them forget about the problems that they have. (p33b, grade 4 , male)

...wanting to wish all their problems away, it's always easy to take the easy way out of a hard situation, I think they just take the easy way out, it's like a way of forgetting. (p52, grade 11 , male)

Oh, sometimes people like want to change or they don't like reality, they want to escape their problems and just like they want to put on a big phony veil to just make everything look better. And to like, make themselves look better when they're like depressed or something. (p56, grade 11, male)

And drugs, and if your parents are fighting and you're having emotional problems at home, you feel like this is one of the only ways that you can, that you're going to feel on top of the world again. (p3, grade 4, female)

Umm, they probably have low self esteem, no confidence maybe family problems, umm, problems with friends or school. Something where they feel insecure and the only escape would be drugs and uh, it's supposedly going to make them feel good, it's the only time they would feel good so they would always want to be using it. (p47, grade 11, female) 
Table 1: Percent of respondents saying drugs are used as means to escape from problems. (pharm-esc)

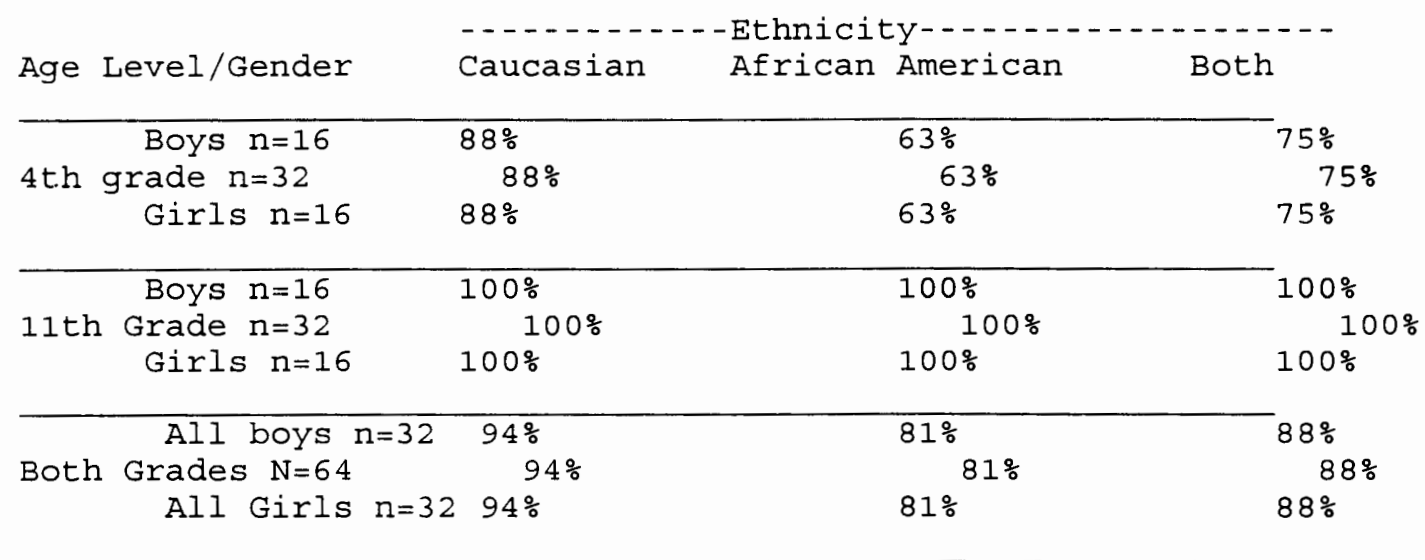

Seeking pleasurable stimulation, excitement or fun from drugs are other reasons given for the use of substances (PHARM-PLEA). It appears this explanation is more meaningful for the eleventh graders than fourth graders. Sixty-three percent of the eleventh graders alluded to the use of drugs for pleasure purposes as compared to only thirty-four percent of the fourth graders, $\left.x^{2}(1, \underline{n}=32)=5.06, \underline{p}<.05\right)$.

Well, people say that it, like, I don't really know, I haven't heard a lot about it, exactly how it feels. But I think they really feel good and sort of dizzy and start, "oh yes", sort of like when they are drunk. (p3, grade 4, female)

Some people do it just cause they like the way it feels. They like the feeling of them. (p33b, grade 4, male)

I guess they don't know any better and, uh, they are persuasive and they'll make you feel good or whatever, and a lot of kids you know they say, like, it'll feel good. (p36, grade 11, male) 
Table 2: Percent of respondents saying drugs are used for pleasurable stimulation or for fun. (pharm-pleas)

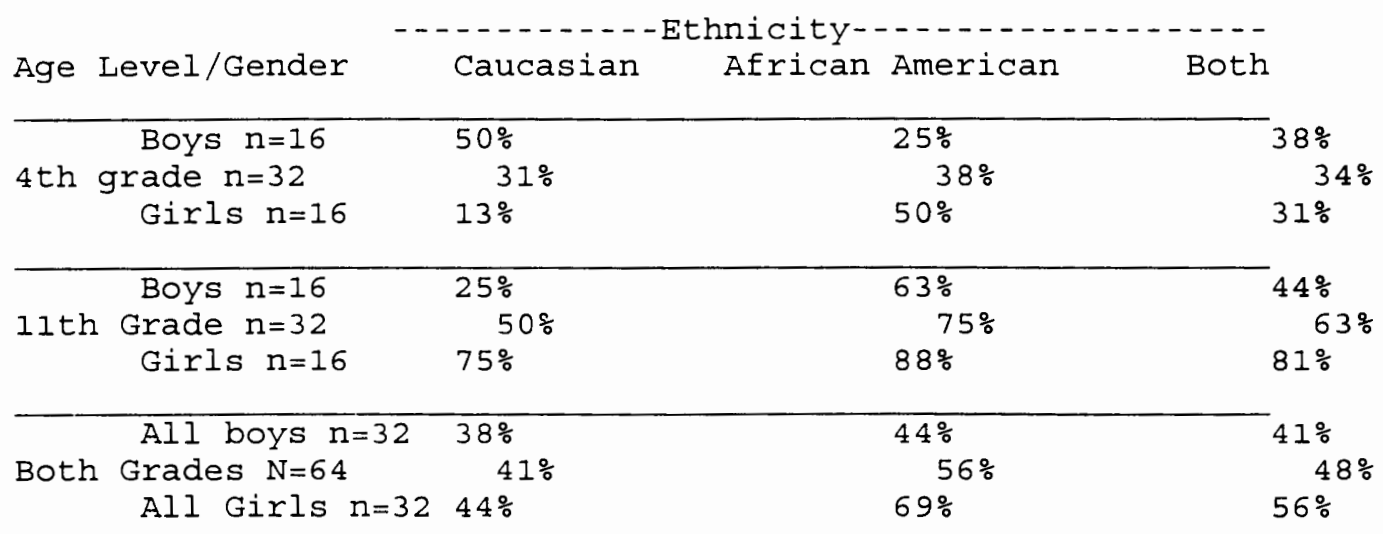

The same situation occurs when the reason of experimentation or curiosity is given for the use of drugs (EXP). Eleventh graders (59\%) more frequently commented that drugs are used for experimentation and exploration than did the fourth graders $(38 \%), X^{2}(1, \underline{n}=32)=4.01$, $p<.05$

Well, there's always the case of the person that is curious, they want to see what it does, they want to see its effects. (p47, grade 11, female)

Kids, they are likely to experiment, they want to try to see what's gonna happen, you know, what's the cause of it, what's the effects of it, you know. Most of the kids like to experiment, you know, see how it feels to do whatever. (p33b, grade 4, male)

I think just because it's that they are experimenting. And, like, later on, after high school, they'll be the group that stops and gets their lives straightened up and there will be the group that doesn't and goes down hill. (p39, grade 11, male)

...probably go over to someone's house and they probably got some marijuana or something over there and I think he's curious and he's kind of scared, but he's curious and he goes on and tries it and I think he thinks he likes it. (p52, grade 11, male) 
Table 3: Percent of respondents indicating that drugs are used for reasons of curiosity or experimentation. $(\exp )$

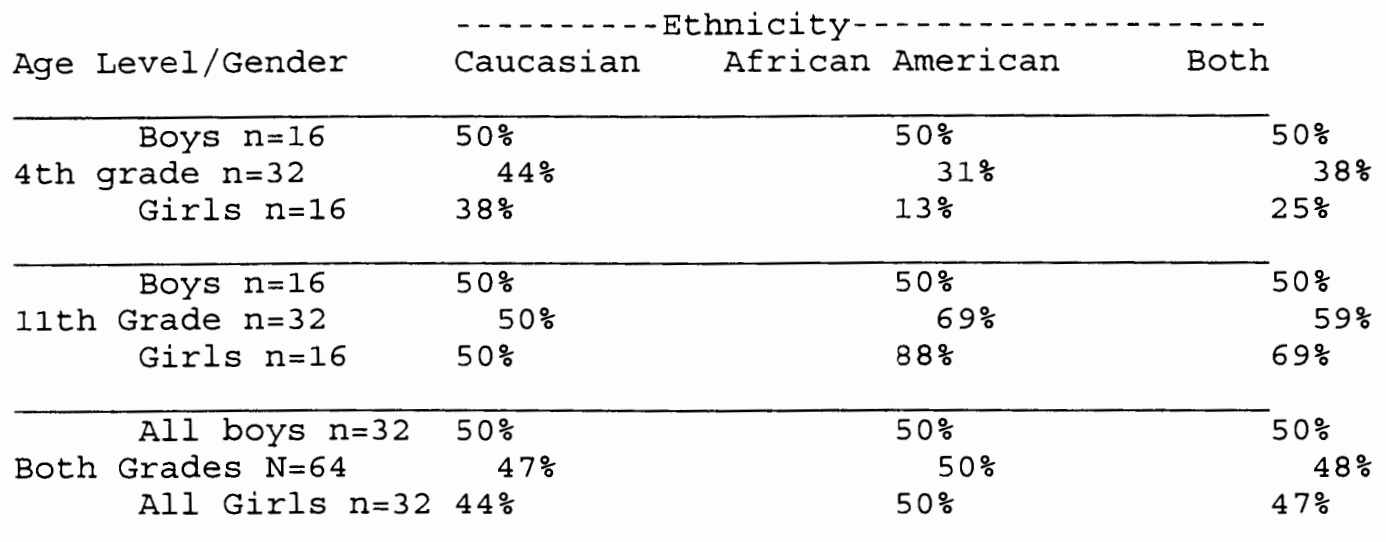

Although given less frequently as a response, overcoming

inhibitions or restraints and increasing sociability was another reason given for drug use (PHARM-OVER). Teenagers quite often feel that if they can just "put down a few beers", then they'll be much less restrained in their social interactions. Eleventh graders were much more likely than the fourth graders to discuss this reason, $x^{2}(1, n=32)$ $=4.01, p<.05$. Caucasians were also significantly more likely than African Americans to mention that drugs are used to overcome constraints or to elevate social facilitation, $\left.\mathrm{x}^{2}(1, \mathrm{n}=32)=4.01, \mathrm{p}<.05\right)$.

Using drugs that you don't, you might think better of yourself or you, uh, the drug is making you think that you are something bigger than you are or something. (p43, grade 11, female)

They'll just feel good and, like, nothing can hurt me, I'm really loose. Just sort of, I can do anything, really. (p27, grade 4 ,
male)

Well, I guess I consider, well, taking alcohol, I always hear, you always hear, I mean, most adults, oh, I'll have a beer and go to 
sleep or go... you know. I don't know what, it's about to relax. Uh, I guess just to mellow out. (p40, grade 11, male)

Table 4: Percent of respondents saying drugs are used to overcome inhibitions and increase sociability. (pharm-over)

\begin{tabular}{cccc} 
Age Level/Gender & Caucasian & African American & Both \\
\hline Boys $n=16$ & $13 \%$ & $0 \%$ & $06 \%$ \\
4th grade $n=32$ & $06 \%$ & $0 \%$ & $03 \%$ \\
Girls $n=16$ & $0 \%$ & $0 \%$ & $25 \%$ \\
\hline Boys $n=16$ & $50 \%$ & $0 \%$ & $19 \%$ \\
11th Grade $n=32$ & $31 \%$ & $06 \%$ & $13 \%$ \\
Girls $n=16$ & $13 \%$ & $13 \%$ & $16 \%$ \\
Bll boys $n=32$ & $31 \%$ & $0 \%$ & $11 \%$ \\
Both Grades $N=64$ & $19 \%$ & $03 \%$ & $06 \%$ \\
All Girls $n=32$ & $06 \%$ & $06 \%$ &
\end{tabular}

\section{Adult modeling}

Young people indicate they want to be more like adults and may model parents or other adults' drug use behaviors. Elementary-aged students in this study demonstrated a susceptibility to the modeled behaviors of parents and other adults. Females were somewhat more Iikely than males to indicate that young people may use drugs based on adult modeling (AUTH-M), by watching parents or other adults and wanting to be more like them, $\mathrm{x}^{2}(1, \mathrm{n}=32)=3.10, \mathrm{p}<.10$. Fourth graders were also somewhat more likely than eleventh graders to note that adult modeling plays a role in promoting drug use behaviors, $\mathrm{x}^{2}(1, \underline{\underline{n}}=32)=3.10, \underline{p}<.10$.

Well, it's really because they have a role model. And their role model probably messes up and they, there's drugs, you know. And so the kids probably think that drugs are good for you. (pl, grade 4, female)

Because they see older people doing it, it's like taking them as a role model. Or their parents do it and they decide, oh, they're 
being cool, so I'll do that too. They think, oh, my parents do it, it's okay. Cause you know, younger kids really look up to their parents. (p17, grade 4, male)

And maybe they see their brother or sister, which I've never seen one of them do. And uh, or they care about them doing it and they uh, they think, if he can do it, I can do it. And uh, really think, well, I want to be a teenager, I want to act older so I'm going to do this. And that's what they try to do. (p23, grade 4, female)

It's like there's a role model and their role model uses drugs and they say, 'if you use drugs, I'm going to use them too. I want to be just like him'. (pl6, grade 4, male)

Table 5: Percent of respondents indicating that drugs are used based on adult modeling. (auth-m)

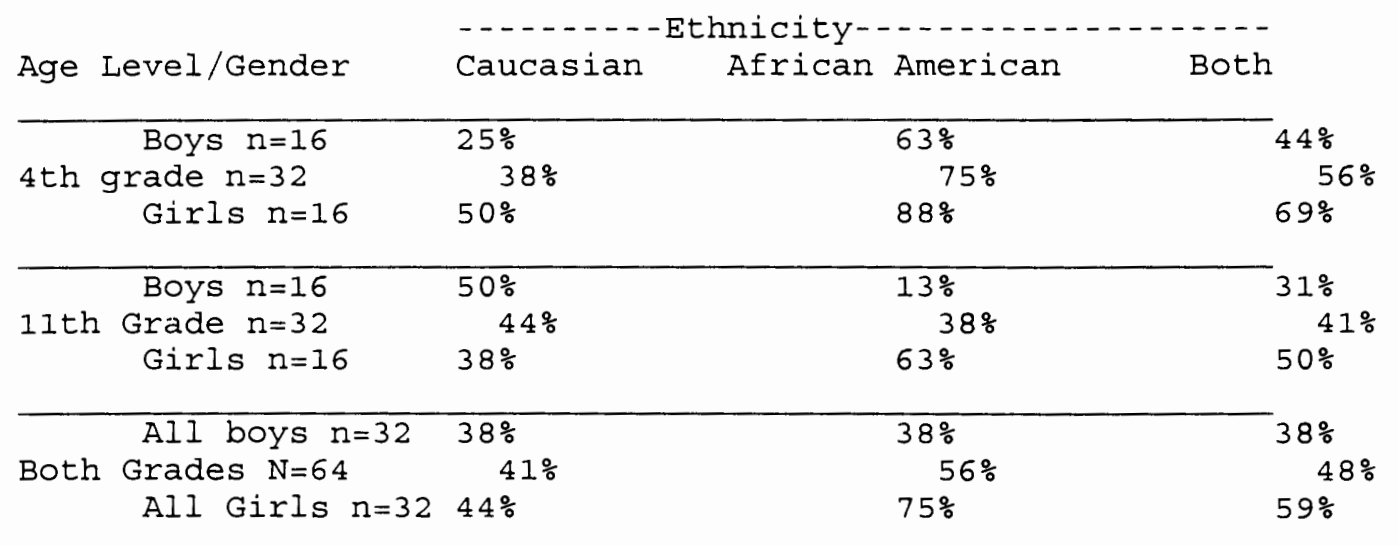

\section{Gender}

Both boys and girls are aware that there is not much of a gender separation in use of drugs. Both males and females felt that there were no major differences in the amount of drugs used or reasons for drug use (GEND-NO), although females (88\%) were more likely than males (53\%) to believe that there were no gender differences in general substance use, $\mathrm{x}^{2}(1, \underline{\underline{n}}=32)=6.06, \underline{\mathrm{p}}<.02$. African Americans (81\%) were also somewhat more likely than Caucasians (59\%) to mention that the gender differences were minimal $\mathrm{x}^{2}(1, \mathrm{n}=32)=3.67, \mathrm{p}<.07$. Examples of this theme are reflected in the following comments. 
Half and half. Like, girls have their reasons and they have some of the boys' reasons. And the boys have some of the girls' reasons and the boys have their own reasons. So you know.... (p25, grade 4, male)

No, I think it's about the same area. Except for one's trying to be a woman and one's trying to be a man. And I'd say it's probably about the same reasons. (p23, grade 4, female)

I think it might all come down to the same reason, umm, family problems. I don't know, I think family problems are kind of like the big thing because that's where everyone kinda comes from and if your roots are kind of screwed up, then what do you have, you know? Umm, I don't know, I have no idea, I think the basis of it would be the same for boys and girls. (p47, grade 11, male)

Table 6: Percent of respondents saying there are no differences by gender in the use of drugs. (gend-no)

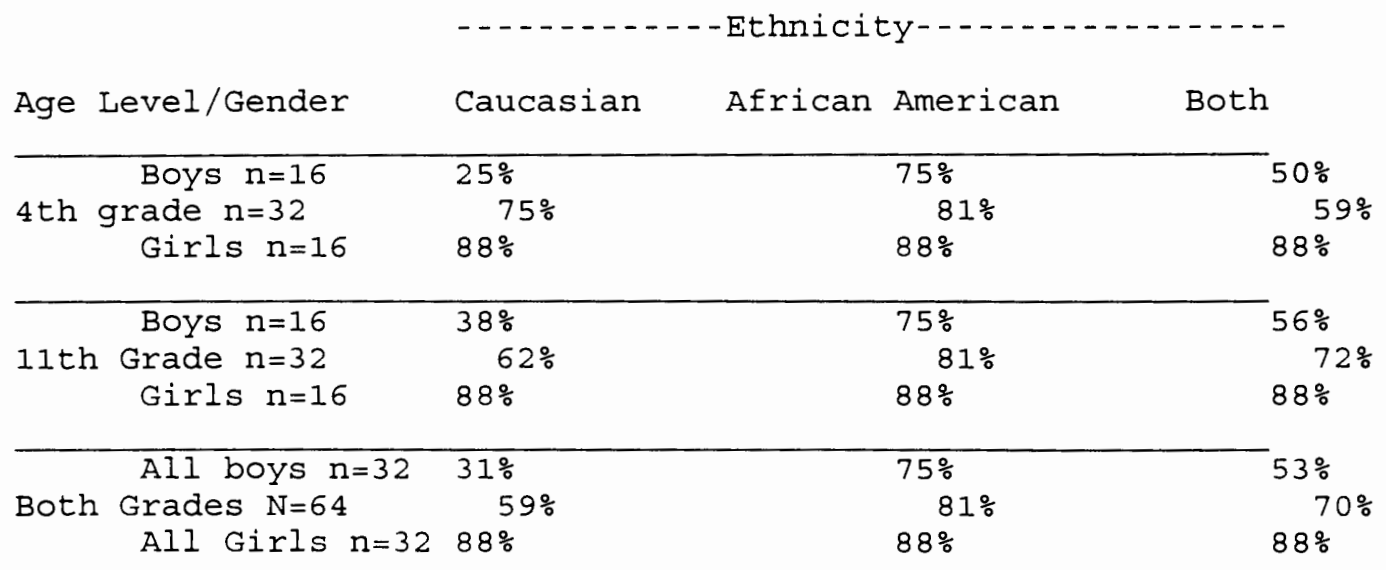

However, when it came to discussing the possible underlying motivation for drug use, significantly more eleventh graders than fourth graders indicated that boys have an image of toughness to live up to and that frequently boys use substances to attract attention (BOY-PROB). older children were more likely to claim that a boy might use drugs to sustain this macho image of being adventurous and performing more risky behaviors, $\mathrm{x}^{2}(1, \underline{\underline{n}}=32)=6.67, \underline{p}<.02$. 
Because a boy probably, you know, he's mad and he wants to just leave the world, so he wants to put up what he's been through. So he just kills himself with drugs. ( 1 , grade 4 , female)

Like guys might have the pressure to be "Mr. Stud". ...He's supposed to be like the tough guy and all this. And like, you know, the athlete and everything. And if he's not perfect up with that, then he feels all, you know, bad about himself and he just escapes. (p46, grade 11, female)

Guys emotionally are different, mentally they're different. Guys are more studly and more ego and that would be a reason to take it where it might not be so in the girl's case you know. (p49, grade 11, female)

Uh yeah. I think guys are more thrill seeking and would try it more, that's just a thing, I just think guys would have a higher risk of trying it than girls. (p53, grade 4, male)

\section{Socio-economic status}

The picture was less clear when the participants responded to the question of which socio-economic group they perceive using drugs more frequently. African Americans (78\%) were somewhat more likely than Caucasians (59\%) to mention that rich kids (UP-MORE) use drugs more or for different reasons than poor kids, $x^{2}(1, \underline{n}=32)=3.47, \underline{p}<.10$. Eleventh graders (88\%) were also significantly more likely to perceive that more "rich kids" are using drugs than were the fourth graders $(50 \%), \mathrm{x}^{2}(1, \underline{\mathrm{n}}=32)=8.57, \underline{\mathrm{p}}<.01$.

The rich probably use them because they got curious, they have so much money and they see it on TV and they wonder how it felt. And they've got enough money to waste, and so they probably waste it, and got curious about addicting. (pl7a, grade 4, male)

... well the rich kids, if they do it, it would probably be because their home life was too strict or something or they were sick of the money or whatever I don't know, they can afford it. (p60a, grade 11 , female)

Yes, you know rich kids, they have the money and they can buy it and then the poor kids, it can take them longer to get the drug than the rich. If you're rich and you have the money and it's just, you know, you have the money, you have it to spend, it's enough for 
you and then you just get more money and a poor kid, can buy just a little and then he ends up either robbing someone and going to jail or getting away and selling it, but they might not give him enough money for it. (p63, grade 11, female)

Well, myself, I know more rich kids who take drugs than poor kids. The poor kids, they don't have that so they use the extra money on clothes and food, whereas the rich person has more money to do what they want and then they have that money to go get the drug and it's a party thing. (p62, grade 11, female)

Table 7: Percent of subjects saying that rich kids are more likely to use drugs. (up-more)

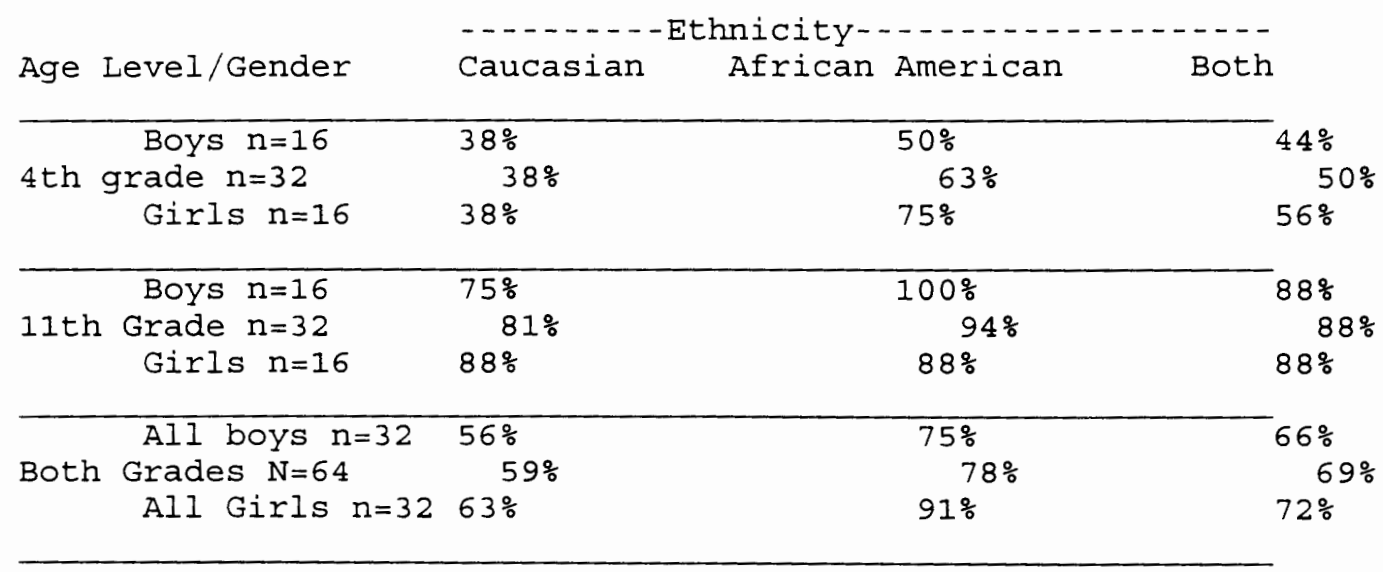

Given the previously noted perception that the upper class might be more likely to use, it is interesting to note that eighty-eight percent of the eleventh graders also mentioned that drug use was similar for both rich and poor kids (SES-ND). This inconsistancy may be indicative of the difficulty young people have separating what they see around them from what they see in the media. The number of eleventh graders mentioning this theme was significantly different from the number of fourth graders $(41 \%)$ that mentioned the same code, $x^{2}(1, \underline{n}=$ $32)=4.01, p<.05$. Moreover, females were much more likely than males 
to indicate that there were no major differences in the amount of drug use between the rich and the poor, $\left.\mathrm{x}^{2}(1, \underline{\mathrm{n}}=32)=4.01 \underline{\mathrm{p}}<.05\right)$.

Some rich kids and some poor kids use, so I think it's like a tie. (p1, grade 4, female)

No, not really (different reasons). Most kids do it for the same reasons. It doesn't matter if they're rich or poor. (p12, grade 4, male)

No, I don't think it's a difference because if a poor person uses drugs, they're going to find a way regardless of money or not, they will find a way to get the drug and the rich person, they're just more accessible to the money, they can get the drug. (p42, grade 11, female)

I don't think there is (a difference). I think that rich kids use drugs just as the poor kids do. You know. Just the poor get treated badly. (p45, grade 11, female)

Table 8: Percent of subjects saying there are no major differences in use between socio-economic groups. (ses-nd)

\begin{tabular}{|c|c|c|c|c|}
\hline \multirow{2}{*}{\multicolumn{2}{|c|}{ Age Level/Gender }} & \multicolumn{3}{|c|}{ 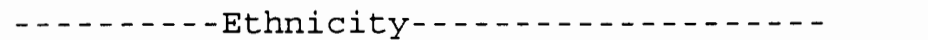 } \\
\hline & & Caucasian & African American & Both \\
\hline \multirow{3}{*}{4 th } & Boys $n=16$ & $38 \%$ & $25 \%$ & $31 \frac{\circ}{0}$ \\
\hline & grade $n=32$ & $38 \%$ & $44 \%$ & $41 \%$ \\
\hline & Girls $\mathrm{n}=16$ & $38 \frac{\circ}{1}$ & $63 \%$ & $50 \%$ \\
\hline \multirow{3}{*}{11 th } & Boys $n=16$ & $50 \%$ & $38 \%$ & $44 \frac{2}{8}$ \\
\hline & Grade $n=32$ & $81 \%$ & $94 \%$ & $88 \%$ \\
\hline & Girls $\mathrm{n}=16$ & $75 \%$ & $100 \%$ & $88 \%$ \\
\hline \multirow{3}{*}{ Both } & All boys $n=32$ & $44 \%$ & $31 \%$ & $38 \%$ \\
\hline & Grades $N=64$ & $50 \%$ & $56 \%$ & $53 \%$ \\
\hline & All Girls $\mathrm{n}=32$ & $56 \%$ & $81 \%$ & $69 \%$ \\
\hline
\end{tabular}

MEDIA INFLUENCES

A high percentage of the respondents felt that there were positive aspects of the anti-drug commercials they view on TV. Ninety-four percent of the fourth graders reported that the commercials were good, 
informative or helpful in some way (COMM-POS-GOOD). This was significantly higher than the number of eleventh graders (66\%) who indicated that the commercials were good or well done, $\mathrm{x}^{2}(1, \underline{\mathrm{n}}=32)=$ 7.82, p<.01. Although not significant, division by gender indicated that females ( $81 \%$ ) were more likely to endorse positive aspects of the commercials than were their male counterparts (78\%), although both percentages were overwhelmingly high.

I think they're the greatest because it helps the kids where their parents don't tell them about drugs and if you watch TV you might see a drug commercial and hear a little more about drugs than you if you don't know anything about drugs.

(p99, grade 11, male)

They're good but they should have other commercials to tell your parents not to take drugs. (p4, grade 4, female)

Oh, I think they are fine, you know. I think it's good and they should have more of them. (p12, grade 4, male)

...the parents will watch the commercial and then the commercial says something like "Don't do drugs" and then their parents will say something like, they'll tell their kids, they'll say "don't do drugs, it's bad for you. (p19, grade 4, female)

I think they are good because when they grow up they won't, they'll think drugs are bad and stuff. Because the anti-drug commercials, they tell them that drugs can hurt your baby and stuff. And it can kill. (p26, grade 4, male)

Yeah, it's like, your brain's frying, you know, and burning and it's like, yeah, I like them, I do. (p44, grade 11, female)

But I think if they keep, if they keep making drug commercials and the anti-drug commercials, I think that maybe the younger generation might seriously consider and think about it before they use a drug. (p48, grade 11, female)

Uh, some of them are really good. Like Nike's using David Robinson, talking about he doesn't like trash in his shoes. And he calls drug dealers trash. (p53, grade 11, male) 
I like them because you know the little kids, they get into those commercials and I think it has some kind of effect on them, like with the egg, this is your brain on one, and the commercial about the father and the son the father walks in and the son started to take drugs and he says he learned it by watching his father, I think that's also a good one. There are a lot of good ones that help stop the younger kids I think and I think for the people that's probably on it and they see these commercials, I think it kind of affects them. (p580, grade 11, female)

Yeah, 'cause a lot of people look up to the famous people and if he's your role model, if you have a famous person as a role model, little kids are gonna see this and say if he's doing that, I want to, they want to be like him or her and yeah, I think that would be a lot better to have celebrities. (p65, male)

Table 9: Percent of respondents indicating that the antidrug commercials are good, informative or helpful in some way. (comm-pos-good)

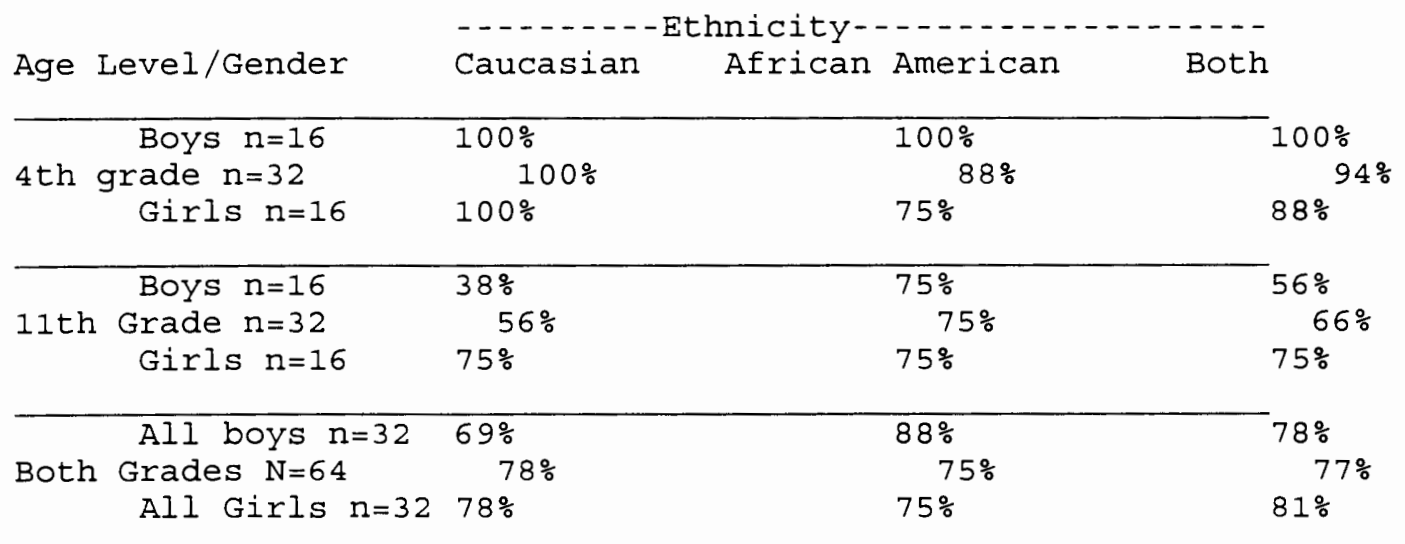

Although many students felt that the anti-drug commercials were helpful in some way, there were some who were critical of them. Some young people claimed that anti-drug commercials may be false or in some way distort reality by minimizing the dangers involved or neglecting to portray the pleasures along with the dangers of drug use (COMM-DIS). Males (28\%) indicated somewhat more frequently than females (9\%) that the commercials were inadequate or distortive $\mathrm{x}^{2}(1, \underline{\mathrm{n}}=32)=3.70$, $p<.07$. In addition, significantly more eleventh graders (56\%) than 
fourth graders (19\%) commented that the commercials are basically

ineffective (COMM-INEFF) in that they may be condescending,

inappropriate or they lack necessary information,

$\mathrm{x}^{2}(1, \underline{n}=32)=9.60, \underline{p}<.01$

I think they don't help any at all. Uh, they are not, they're mostly worthless. Usually kids that do listen to those are kids that are already in drugs and they laugh, they laugh in their faces. But, I think they are meant to do well but they're not, they don't do anything. (p3, grade 4, female)

When they say it they should have an alternative or something I don't know cause a kid can't do something he's gonna want to do something else so on the commercial they an alternative like don't do drugs, you shouldn't do drugs, something like keep your mind on books. (p57, grade 11, female)

I wish they would just, you know, give you more information because some are just too short, it just almost seems stupid. (p48, grade 11, female)

...it's because usually people lie on commercials and stuff you know and like I said on the movies, or you asked me what, if you think that this is what happened in real life? Like I said, "No", because I don't think that's the way it is in real life. But uh, the way they show it, I think they are worthless. (p53, grade 11, male)

Because people think they'll start with it, like this other commercial, and then your life will be over and it will all end. But no one believes that. Because of all the lives that are going on. So it needs to show that your life may not end, but it still will be really bad. (p46, grade 11, female)

Like I said, "no", because I don't think that's the way it is in real life. But, uh, these kids, the way they show it, uh, I think they are worthless. (p3, grade 4, female) 
Table 10: Percent of respondents indicating that the antidrug commercials may be false or in some way distort reallity. (comm-dis)

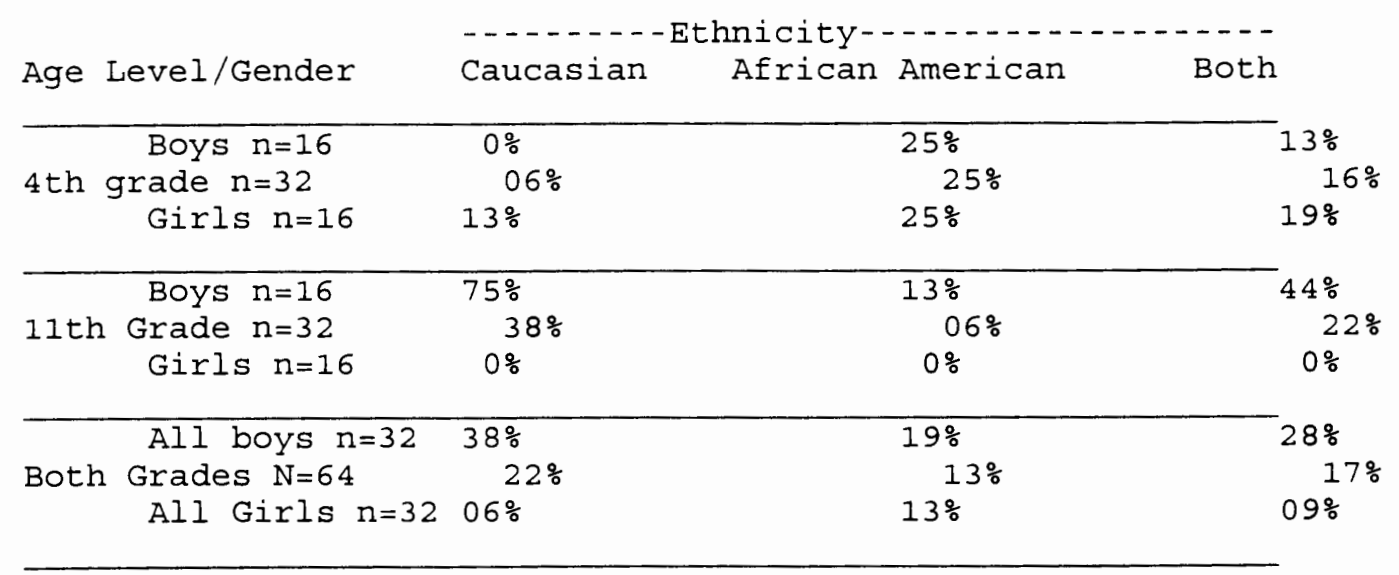

Table 11: Percent of respondents indicating that the antidrug commercials are condescending or basically ineffective. (comm-ineff)

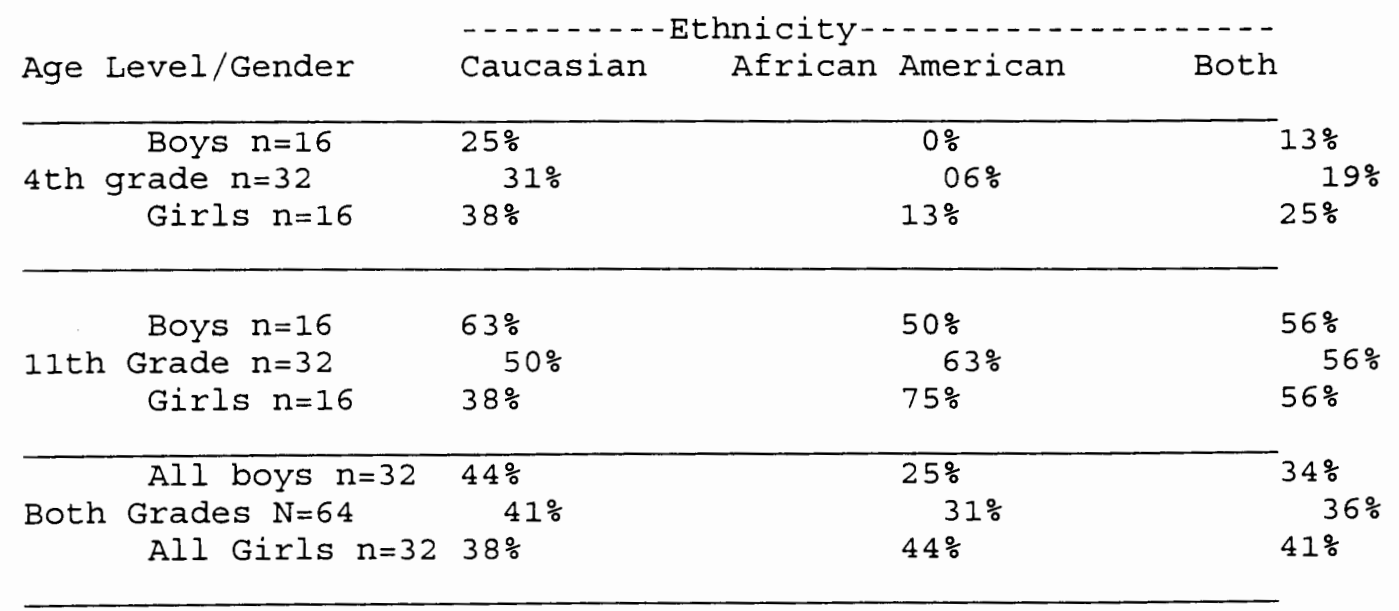

Eleventh graders were more apt to discuss their reservations regarding the motives of some of the actors used in the anti-drug spots (COMM-HYP). Some participants indicated that actors may just be doing it for the money and in reality have little concern for the targeted 
audience. Twenty-eight percent of the eleventh graders and only one of

the fourth graders made statements relative to this notion

$\mathrm{x}^{2}(1, \underline{\mathrm{n}}=32)=7.59, \underline{\mathrm{p}}<.01$.

Well, I don't think too much of them because most of them are getting paid and most of the famous people are using alcohol or drugs. (p42, grade 11, female)

Well sometimes they're just paid to say that and they smoke or do something. (p17, grade 4, female)

Sometimes you know, some of the famous people, sometimes I wonder if they're doing it for the publicity or if they're doing it because they really don't want society to use them. Because you look at them and wonder if they've used drugs themselves and if they're being kind of two-faced you know.

(p48, grade 11, female)

Table 12: Percent of respondents indicating their

reservations regarding the motives of actors in

the anti-drug commercials. (comm-hyp)

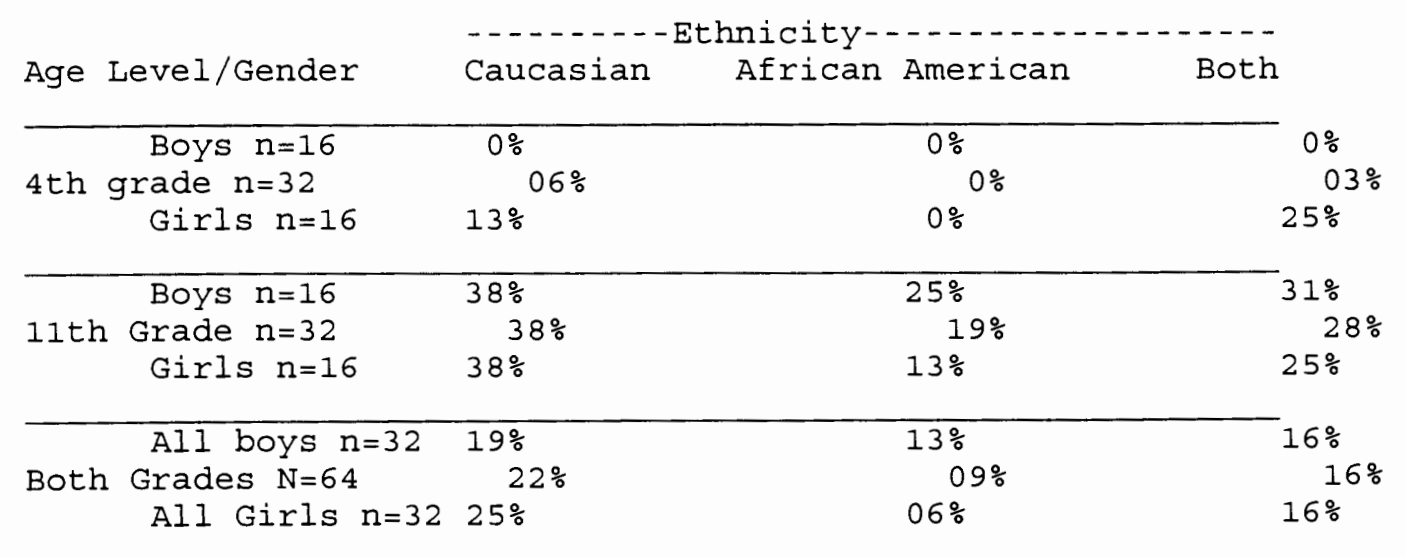

"Just Say NO"

The "Just Say NO" program was designed to provide an easy response for young people when approached by others wanting them to use drugs.

The program was primarily intended for younger children as a way to deal with pressure from others. When participants in the present study were 
asked whether they feel the "Just Say No" program is an effective way of dealing with the problem and whether their friends think it is useful, significantly more fourth than eleventh graders indicated that the campaign is positive or useful and helps remind kids that drugs are bad (JUST-POS). Seventy-five percent of the fourth graders had positive comments regarding the program while only thirty-one percent of the eleventh graders felt the campaign was effective $x^{2}(1, \underline{n}=32)=12.31$, $\mathrm{p}<.01$.

I think they are right. I think they should keep doing it and if, if people don't believe in this rule then that's their own problem and some other people might. And if they keep doing it, they can't stop them. Because other people have their rights too. They can say "take drugs" but other people can say "don't take drugs." (p5, grade 4, male)

I think it's pretty neat that they do that. (p14, grade 4, male)

Yeah, because the kids that aren't high on drugs, and they, they know if they want to be on drugs they can, they can go at their own risk. But they know they can also just say no, just, they won't bother them again, unless these guys are stupid and say, "you can try it, these are good, really good". But you've just got to say no and they'll probably just leave you alone.

(p25, grade 4, male)

Table 13: Percent of respondents indicating that the "Just Say No" campaign has positive aspects. (just-pos)

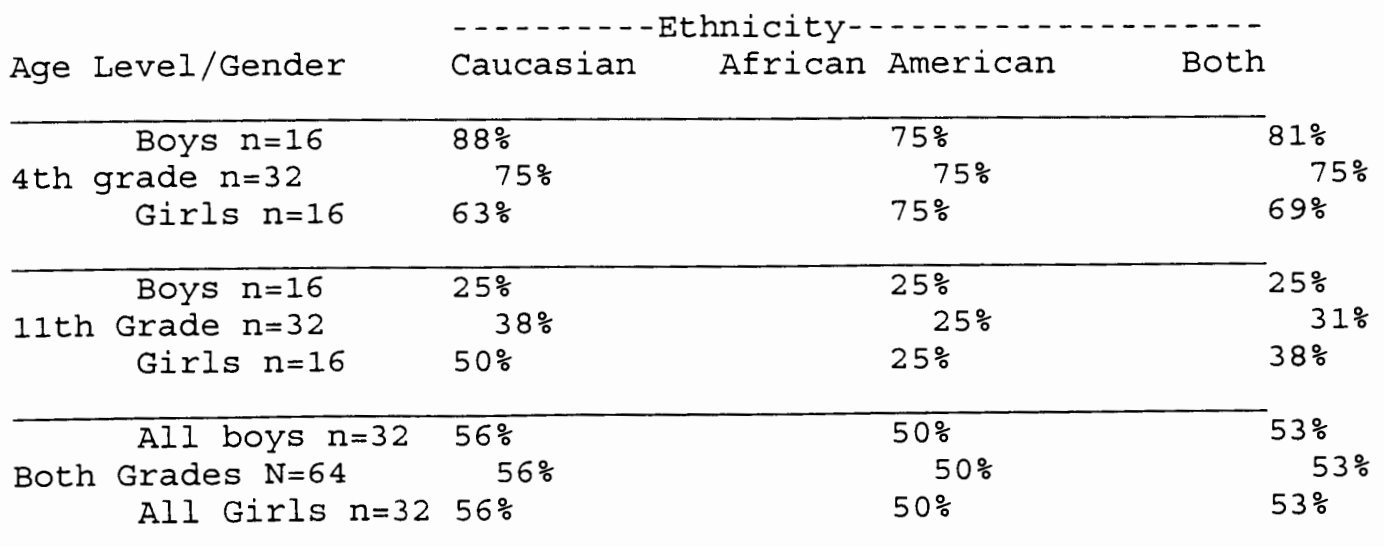


In contrast to the fourth graders who were apt to like the "Just

Say No" program were the eleventh graders who responded with critical

comments about the campaign (JUST-CRIT). Many regarded it as too

simplistic or without substance. Only twenty-two percent of the fourth

graders had negative remarks while seventy-two percent of the eleventh

graders offered negative comments $x^{2}(1, \underline{n}=32)=16.06, \underline{p}<.01$.

Like after sixth grade, you start getting independent and stuff. When it's your body, you want to try it. And it wouldn't matter if there was a Iittle button that said, "Just say no". It wouldn't stop anyone. (p39, grade 11, male)

It's appropriate for that age, but it's just brain wash for that age in my mind. (p40, grade 11, male)

I think they should be saying more. Because all they really say is 'Just say no'. That's all you have to do? It's not really that way, it's really hard, there's a lot of pressure. It's a lot more complicated because some kids, they, like, get threatened with their life and they get threatened with to get in trouble if you don't take drugs. I think it's a little more complicated than just say 'no'. (p23, grade 4, female)

No, I don't think anyone cares if Nancy Reagan says, "Just say no." (P45, grade 11, female)

I used to think "just say no" was cute, but that you should tell them what they are saying "no" to. Not just say "no" to drugs, you should teli them why they should say "no" to drugs. Give them the information on why the drug, why they should just say "no", cause if you just say "no" to drugs, or "no don't do drugs", you know somebody is gonna wonder why shouldn't I? You know they don't tell you shouldn't, they just tell you to "just say no". Just like in the commercials, they should give more information cause that's just gonna make a person more curious, why do they want me to say "no"? Maybe I should try it or something. They want to know why they don't tell you that, they say to "just say no" to drugs. (p63, grade 11, female) 
Table 14: Percent of subjects responding with critical comments regarding the "Just Say No" program. (just-crit)

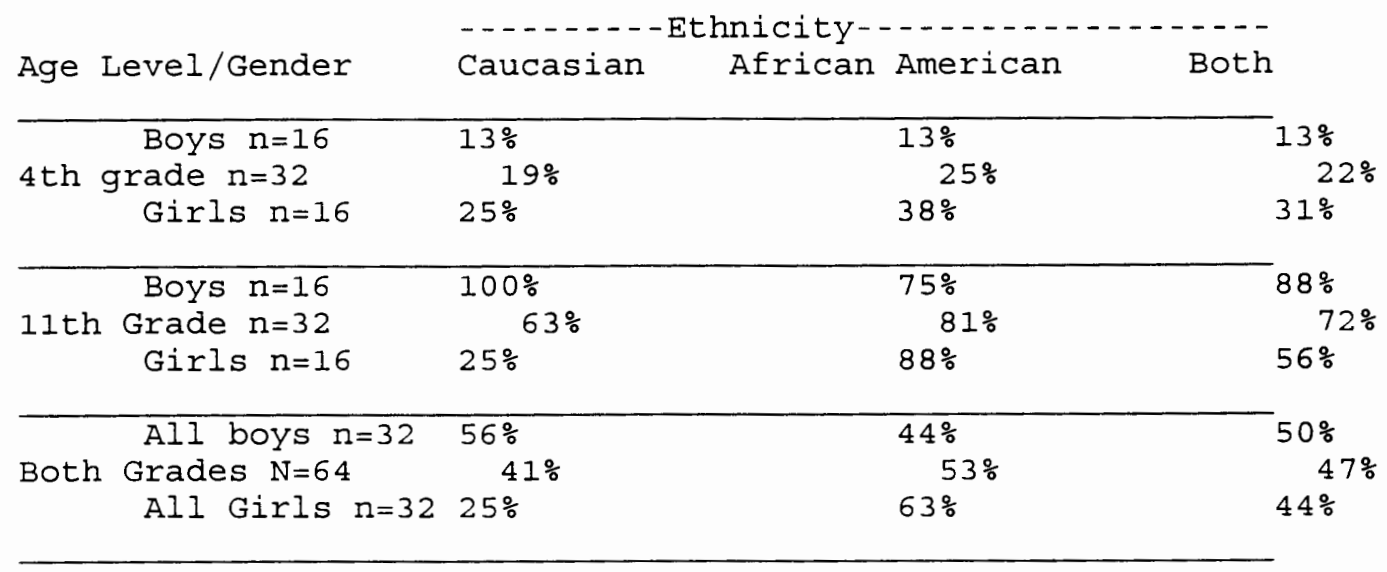

Often there is a stereotypic display of particular groups in the media. When asked if certain groups are shown to use drugs more than others or if they thought the way they are shown is really true, most of the participants recognized that there may be some misrepresentation. "Yeah, like they show, all they ever show are gang members that are black. They never show any white ones, they just show black, black, black, black, BLACK!".

Not only are many youth aware of this misrepresentation in the media, but they are also critical of the portrayal. The high school participants were particularly aware of media misrepresentation. One eleventh grader commented: "Oh yeah, like blacks are exploited just totally. I mean, you never, you never see white people smoking crack. It's always in some New York ghetto that is just ninety-nine percent Black". Teenagers are especially sensitive to how they are being portrayed and how they feel they are stereotyped along with other groups that are negatively characterized. "When they show people that are 
using drugs, they usually show them as dirty, scummy, you know, not good for society, usually as being teenagers, usually getting bad grades, not going to school, not obeying their parents, or you know, you usually see them as being a negative person". 
CHAPTER FOUR

DISCUSSION

This study explored young persons' perceptions of the relationship between drug use and social phenomena associated with drugs. The respondents were also asked for their conceptions and analyses of the effect on drug use of larger social influences, such as the information they receive in school and the mass media. The appeal of this study lies in the richness of the information provided by these young people as they discussed issues that are very relevant in their lives. Their insights and criticisms provide an important vantage point from which to view those directly influenced by drugs.

\section{REASONS FOR DRUG USE}

When young people were given the opportunity to discuss why they think their peers start using drugs they provided many reasons. They confirmed previous research that indicates that the peer group is a primary facilitator of drug use (Oetting \& Beauvais, 1987). Both eleventh and fourth graders indicated that obtaining and keeping friends is an extremely important part of their lives. Young people seem to have a deep desire for group identity and want to belong. They often conform to any activities of the group to be popular or to avoid being seen as stupid or "nerdy". 
Frequently the activities within the peer group surround the experimentation and use of various mind altering substances. If young people are involved in activities where drugs are available, it is somewhat difficult for them to go contrary to the direction of their friends. When they see their friends or individuals they would like to have for friends using drugs, there is a great deal of pressure to accompany them in these activities. Young persons repeatedly mentioned that, in order to keep their friends, they feel they must use, or be ostracized for not being "cool". "Their friends say that it's cool and it'll help you and if you want to be cool like us, then you can do it. And they believe them and they do it" (p12, male, fourth grade). Even when they know that drugs are dangerous and that they probably should not use them, young persons may still use to maintain the company of their friends.

Moreover, while there are individual differences that may predispose an individual to more actively seek out drug use experiences, the experimentation with and use of drugs are nearly always realized through contact with friends or family members.

Respondents were given the opportunity to discuss why young people get involved with drugs in the first place. They were also asked to speculate on the way larger societal influences such as the media and television might affect drug behavior. Peers play an increasingly important role in the life of adolescents as they seek independence and strive to become a part of the world around them. Peers are also involved to a large extent in modeling behaviors, some of which involve initiating other friends into the use of drugs. 
All the participants, both fourth and eleventh graders, mentioned that their friends play a role in promoting or discouraging drug use. Pisano and Rooney (1988) noted that there are significant increases in susceptibility to peer influences that begin as early as the fourth grade and continue through the higher grades. They note that "these changes in attitudes correspond closely to the shifting of importance of parental guidance to peer companionship" (p. 9). Friends assist in either providing the motivation or the opportunity to use drugs. "Well, when you are doing drugs, you make friends better, you know, they think drugs are cool" (p55, female, eleventh grade). In order to be part of the "in crowd" many young people feel they must participate in these activities, or be left out. "Yeah, they do it because it's cool, because their friends do it. And they think if their friends do it, they should do it"(p45, female, eleventh grade). "Because they think it's cool and they think they will lose their friend if they don't do it" (p4, female, fourth grade).

One eleventh grader discussed just how important friends are to her and illustrated why the peer group can have so much control over the thinking of high school kids. "Cause it's, like, now I remember my freshman year. That was the number one most important thing for me. It was to have friends and be socially adequate. I just didn't, and obviously I used drugs to fit in, you know, that was my thing" (p45, female, eleventh grade).

When teenagers are faced with opportunities to be involved in problematic behaviors it becomes extremely difficult for them to go contrary to expectations of the group. Even though they may have been 
previously taught of the dangers involved by their parents, teachers and other adults, the situation that they are in seems to lessen all the previously learned information and they still conform to what the group is doing. Fear may well be a motivating factor in promoting this type of conformity. One eleventh grader expressed a concern of young people: "So I think that the reasons that some kids do drugs is because they see their friend, you know, they want to keep their friend and their friend says, 'Hey, if you don't do drugs, I'm never going to be your best friend' and it might be the only friend that you have" (p57, female, eleventh grade).

Young persons also indicate that drugs are frequently used to escape from problems and the pressures of everyday living and are often used as a means of relieving anxiety. This would coincide with the findings of Labouvie, Pandina and Johnson (1991) who suggest that initiation and subsequent higher levels of use are linked to chronic problems including failure in school and more chronic exposure to disruptive and stressful life events. Young people face the challenges of doing well in school while balancing pressure from their peer group and their families. Although they mostly understand that certain substances might be harmful, they feel that drugs may provide an occasional way out and try to escape in this manner. Respondents noted that drugs are seen as a way to overcome constraints by providing a pleasurable state and increasing sociability. The self esteem of many students may be precarious and some have very little confidence, especially in school and other demand settings where inadequate performance may impair self esteem. Silbereisen and Noack 
(1988) indicate that drinking and smoking may be a means of integrating the young person into the peer context. This group acceptance, especially in middle adolescence, might possibly be responsible for a subsequent gain in self esteem.

In addition, there are young people who are curious about the way drugs make you feel and simply want to experiment with different sensations and feelings. Adults around them are expending a great deal of energy to keep them from using. High school students (eleventh graders in this study) are especially interested in understanding new sensations. "Kids, they are likely to experiment, they want to try to see what's gonna happen, what's the effects of it you know" (p50, male, eleventh grade).

And finally, some youth indicated that their peers use drugs because adults use them and they want to be more like adults. Parents may have a standard for their teenager that is different from their own behavior. Teenagers are required to sort out the messages they receive from their parents and other adults and act accordingly. This may include modeling the drug use behavior of other adults or making attempts to contradict some of the norms they've been given. Either way it is likely to attract the attention of their parents signaling them to become more involved in the situation.

\section{GROUP DIFFERENCES}

Young people understand and perceive that the "war on drugs" has taken on a great social significance. They hear anti-drug messages in 
the classroom and see them portrayed in the media. They see fellow students using drugs at school, and some have participated with them in these behaviors.

Although society as a whole has tended to believe that certain groups are more likely to use than others, young people have their own views of patterns of use. Male adolescents have often been targeted as potential users and therefore are more likely to be involved in intervention strategies. Minorities, low income groups and teenagers in gangs have also been recipients of increased attention.

The discriminating lines across groups are not nearly as clear in the eyes of young people. Many see drug use around them and know that while many of their fellow classmates are involved, it is not necessarily one specific group. Pisano and Rooney (1988) indicated that while statistically different, the differences between the sexes in consumption of beer and wine are small. Moreover, there was no significant difference in the use of cigarettes by sex nor differences in general attitudes toward alcohol or cigarette use. Respondents in the present study were equally likely to believe that either a girl or a boy may be using some sort of drug. According to these students, girls and boys face similar challenges in their lives; respondents noted that the reasons given for drug use are applicable to both genders.

Even with the perception that drug use is similar for the genders, the notion still persists that males are more macho and adventurous and must be involved in these risky behaviors to maintain an image. Society has modeled that macho image and made it appealing to many young men. And while as many young women are involved in risky behaviors such as 
drug use, the male is more apt to use this as a form of prestige. "Guys are more studly and have more ego and that would be a reason to take it where it might not be so in the girls' case you know" (p49, female, eleventh grade).

Young people presented an ambiguous picture when they discussed drug use with reference to socio-economic status. A large number of students believe that those with more available money will use and experiment with drugs more than those with less resources. They understand that drugs are expensive and require extra funds to obtain them. They believe that kids from more wealthy families have the money to spend and often spend it on drugs. However, many participants still believed that just as many poor people use drugs as rich people-they just use different means to obtain them. If a person with less cash wants to purchase drugs, he/she may become involved in more creative activities to acquire them, some of which may be illegal.

\section{MEDIA INFLUENCES}

Communication in all its formats is considerable in this "information age". Young people encounter a vast array of information that they must evaluate and act upon. The media, especially television, have become a primary source for much of the information children and adolescents receive (Dan, 1992). Although television mirrors many of the negative aspects of our society such as violence and other antisocial behaviors, program planners feel that this medium also might convey some useful messages regarding the use of alcohol and drugs. 
Anti-drug commercials have been broadcast in an effort to both educate and warn youth of the impending dangers associated with the use of many substances. There is a continuing effort to determine if these TV spots have achieved their goal of affecting attitudes and promoting drug free behaviors. Unfortunately, some youth believe these media messages have missed their objective and end up either misdirecting or insulting their viewers.

The media also shape the way young people think about their world and this is true with regard to certain substances, especially alcohol. Embedded in much of the programming are messages, whether intentional or unintentional, that promote certain behaviors and lifestyles. For example, television has glamorized the lifestyle of the "beer drinker" by associating beer drinkers with attractive, fun people and energetic lifestyles. It is not uncommon for a youngster in one moment to see a commercial with a young person refusing a drink from one of his/her peers and in the next instant see one of his/her favorite athletes having fun and drinking beer in another commercial.

There are indications that students are aware that there are mixed messages in the media and they comment on the dilemmas the messages create. "I mean we've got the anti-drug messages, but then we've got the more subtle messages of the beer posters. You go to the football game or to the beach and they are playing volleyball with all these beautiful women. I mean, people see that and they're not really thinking alcohol's good, but they still get the impression of it (alcohol's good). I can say that a lot of advertising contributes to people being alcoholics and things like that, you know. Just the whole 
cool-guy image of going out and slamming a few beers or whatever" (p37, male, eleventh grade). This may be anecdotal evidence for the concerns of Signorielli (1987) that television may be providing messages that drinking is "ok" and may be an acceptable part of social encounters. The media also inadvertently shapes the way society views different groups by their persistent stereotypic display of drug-prone groups. Young people, gang members, people of color, lower income or homeless people are often portrayed as those most involved in illicit use and distribution of drugs.

Participants provided a great deal of feedback regarding their views of the commercials they see on television. Students observe that to a large extent the commercials are informative and are helpful in some way. The overtone of many of the comments was that the commercials are good and are teaching useful messages. In many instances exact commercials were recalled and given as support for what the respondent was saying. The commercial most frequently referred to was the one with the egg frying being compared to "your brain on drugs".

Erickson et al. (1990) have noted that there is increasing evidence that the mass media can produce meaningful, albeit modest, changes in behavior. They advocate the media become the socialpolitical arm of public health promotion, supplementing the more traditional school and public health education programs.

once again research provides evidence that media programs should be carefully tailored for various age groups. Ninety-six percent of the population watches television an average of 3 hours a day, with children and older Americans watching even more (Arkin, 1990). Younger 
respondents in this study had positive opinions toward the commercials and felt they are effective. Some liked the fact that the commercials are short and to the point: "Great, I mean it is straight to the point. 'This is your brain on drugs.' If you see that egg frying and you think of that being your brain, you can't get any closer than that. It's straight to the point" (p62, female, eleventh grade).

of equal importance are the negative comments provided by some of the high school viewers. While they thought anti-drug commercials might be useful for younger children, many of the older respondents feel they are not necessarily applicable to them. They were quick to note faults in either the presentation or the presenter of the message. Any individuals promoting lifestyles or activities that might be inconsistent with their image would frequently be dismissed as a hypocrite. Eleventh graders were frequently suspicious of the motives of many adults and celebrities and many were prone to dismiss their advice when they found contradictions.

Teenagers were critical of commercials that tend to distort reality or portray inaccurately the effects of drugs. "Like I said, 'no', because that's not the way it is in real life, I think they are worthless" (p56, male, eleventh grade). They know that they will not immediately die if they smoke marijuana or try crack. So when they see a commercial that delivers a message that essentially says they will go up in a "poof" of smoke if they try a drug, it diminishes their trust in all the messages.

Arkin (1990) cautions mass media professionals not to exaggerate health risks to increase attention and warned against exploiting the 
emotions of the public. She encouraged responsible reporting of the information in a manner which audiences will read and listen to rather than information that is intended to produce a particular public response. Arkin provided a list of strategies for improving the quality of the mass media wherein she called for continued research into the impact of health imagery on various audiences.

THE "JUST SAY NO" CAMPAIGN

Current anti-drug curricula have been in the schools for several years now. Teachers have been discussing these issues with young people and have endeavored to inform them of the dangers involved. Teachers, as well as celebrities, have encouraged youth to "Just say No" when encountering a situation involving drug use.

Fourth graders were more receptive to this simple message and indicated that it is helpful in some cases. A large portion of the Eourth graders had positive comments regarding the program and felt that it was helpful in some way. "Oh I think that's pretty neat that they do that. Because they like some really famous person and they might want to look like them and be like them and they might think, well, if she's not going to be, if she doesn't smoke, then I'm not going to smoke and if she says 'no', then I'm going to say 'no'" (pll, female, fourth grade).

Once again, the older students were more critical and observed that the program is inadequate in some ways and does not deter drug experimentation or use. Many of them concurred with kelly (1991) that the "Just say No" campaign is simplistic and insufficient to influence 
behavior. "I think it's ok, but it doesn't really affect a lot of the people. I think it makes no sense at all. Because umm, say 'no', who are they talking about saying 'no' to? Yourself or your parents, or you know, say 'no' to peer pressure. I think it's more like people search it out, people look for it" (p46, female, eleventh grade). In addition, many of the older participants felt that the program was effective only in the younger age groups and had little impact on their lives.

Some of the eleventh graders were critical of the mixed messages society provides them. While teachers and many adults are warning them of the evils of many substances, other adults as well as the media are luring them into experimentation and use. One eleventh grader noted: "It's just kind of, just white washing the whole thing. 'Just say no to drugs,' you know, but then of course there are billboards everywhere showing women with hardly any clothes on you know, people sure don't say 'no' to that. You know, that's our culture right there" (p37, male, eleventh grade).

The younger participants seemed to be more receptive and willing to follow the celebrities' advice to "Just Say No". One fourth grader responded: "But most of the time they're pretty serious and kids listen to people like Bo Jackson and stuff like that. They will, I guess think that it's not cool to take drugs if he doesn't, you know" (p15, male, fourth grade). This age difference in acceptance of the program indicates that campaigns such as these should be carefully targeted to the appropriate age. 
LIMITATIONS OF THIS STUDY

The participants were recruited from within classrooms during the school day, thereby limiting the pool to those students attending and willing to participate. Including students from sources other than the school system may have reached those individuals either involved directly in the use of substances or closest to drug use in their families.

There are also limitations in the use of the cross-sectional methodology. Many of the age differences discussed herein may be due entirely or in part to cohort differences or the different histories each group experienced. The media sections are especially problematic when considering the different types of programming to which students were exposed in the 1970 s and the 1980 s (the 11 th graders) as opposed to 1980 s and the 1990s (the 4 th graders). Had the older participants been exposed to similar media efforts and educational campaigns, some of their perceptions of these programs may have been altered. On the other hand, some of the differences uncovered in the present study may be true age differences that would be demonstrated regardless of when the study was done.

An example would be the extent to which the younger respondents were impressed by the commercials on TV and the "Just say No" campaign while the older students were more critical of the programs. Older adolescents are less likely to see things in absolute or merely black and white terms. Following these younger students longitudinally into their teenage years and reassessing their opinions would provide some 
indication of changes in opinion that come with cognitive development. It may be that as young people grow cognitively and thereby understand and interpret social complexities more effectively, they become aware of inadequacies in some adult representations of issues and more critical of superficial solutions to problems. A longitudinal study would provide some indication of the cognitive growth that occurs as young people mature and the way social interaction shapes thought processes at various points in development.

\section{FUTURE RESEARCH}

There were two sections of the interview not included in this paper that may provide interesting information regarding young persons' perceptions of drugs in society. One area is the role young people see the government taking in the fight against problematic substance use. Do students perceive that problems substantially exist outside the United states and are infiltrating "our world" or do they think the problems are created form within?

Equally interesting would be young persons' view of the role government plays in the prosecution of individuals involved in substance use and abuse. Is the emphasis for prosecution equally distributed across all ethnic and economic groups, or is there a tendency to scapegoat certain groups as primarily responsible?

It would also be interesting to investigate the amount and quality of discussion occurring between young people and their parents. Do teenagers feel comfortable discussing a sensitive issue such as drugs 
with their parents or other adults? A clearer understanding of the type of communication that occurs between parents and their children would provide information that could be used to facilitate better and more complete dialogue in the future. 
CHAPTER FIVE

SUMMARY AND CONCLUSION

It was the goal of this study to allow young people to discuss their thoughts and thereby add their opinions and perceptions to the dialogue surrounding current drug use issues. The overall findings of this study demonstrate that there are differences that can be attributed to age and or cohort which become evident from the discussion with these young people. Differences due to gender and ethnicity are less robust, yet are still interesting.

In considering the use of drugs, older adolescents commented that drugs may be used to overcome constraints, escape from certain situations or simply for experimentation and pleasure. They indicated that boys are more likely to use as a result of challenges in their lives and noted that the upper class are also more likely to use. Eleventh graders were also more critical of the commercials they view on television and less likely to respond positively regarding the "Just Say NO" program. Fourth graders were more positive in their responses to the anti-drug commercials and the "Just Say No" campaign. Longitudinal research following these students would provide useful information on the long term effects of these programs as well as on the cognitive development that occurs as young people mature and become more critical of the world around them. 
Young persons are still greatly influenced by their friends and want to be part of the in-group. As noted by Pisano and Rooney (1988), the shifting of attitudes away from parents to the peer groups may begin as early as the fourth grade. As peer influence grows and attitudes of young people toward drug use become more positive, use will increase. As attitudes toward use become more positive, anti-drug messages may have a reduced effect. Therefore, prevention efforts that tend to either isolate the youth from friends who are using drugs, or discourage the whole group from using may produce desired results. Moreover, programs that can effectively change the attitude of each member while maintaining the accurate perception that not "everybody" is doing drugs are also likely to demonstrate positive results.

MEDIA

The motivations surrounding the initiation of drug use and their continued use are complex. Young people often face the overwhelming task of sorting out the many messages they receive about drugs and trying to deal with them as best as possible. Society can aid young people by providing them with knowledge, resources and an environment that would help them best cope with these challenges.

The media are playing an increasingly larger role in the lives of young people. It has become especially important to educate younger children who are the prime consumers of TV. Television not only provides them with information, but it also influences their attitudes and feelings regarding many things. Efforts must be made to use 
effective media programs that provide accurate information and promote anti-drug messages. More subtle messages that accompany many advertising campaigns must also be scrutinized.

Nationally televised campaigns can be used to stimulate and promote local community organizations. These organizations can funnel energy aroused by the media and anti-drug programs and transform this energy into positive results. These organizations can promote more parental involvement in schools and in the lives of their children as well as participation in other related community affairs. In that way each community can respond to its own needs and address specific concerns of youth.

Programs such as the "Just say no" campaign should consider the age of the target population and tailor the program to meet the needs of this group. Simple programs that use popular characters who have a wide appeal are most likely to have an effect with younger children.

It is evident that young people need to be involved in the process of reducing drug use and abuse in our communities. Programs that simply try to control behaviors are Iimited in the information they provide and the dialogue they produce. Young people have a first hand view of the challenges associated with drug use and can provide useful information pertaining to drug use issues. Involving them in the dialogue will provide a clearer understanding of the influences they encounter and thereby enable researchers to effectively counter these pressures in a positive direction. 


\section{Bibliography}

Arkin, E. B. (1990). Opportunities for improving the nation's health through collaboration with the mass media. Public Health Reports, 105(3), 219-223.

Bachman, J. G., Johnston, L. D., \& O'Malley, P. M. (1988). Explaining the recent decline in marijuana use: differentiating the effects of perceived risks, disapproval, and general lifestyle factors. Journal of Health and Social Behavior, 29, 92-112.

Berndt, T. J. (1979). Developmental changes in conformity to peers and parents. Developmental Psychology, $\underline{25}(6), 608-616$.

Biddle, B. J., Bank, B. J., \& Smith, M. M. (1980). Social determinants of adolescent drinking. Journal of studies on Alcohol, 41, 215-241.

Blount, W. R., \& Dembo, R. (1984). The effect of perceived neighborhood setting on self-reported tobacco, alcohol and marijauna use among inner-city minority junior high school youth. The International Journal of the Addictions, 29, 175-198.

Brown, B. B., Clasen, D. R., \& Eicher, S. E. (1986). Perceptions of peer pressure, peer conformity dispositions and self-reported behavior among adolecents. Developmental Psycholgy, 22(4), 521-530.

Collins, D., \& Cellucci, T. (1991). effects of a school based alcohol education program with a media prevention component. Psychological Reports, 69, 191-197.

Dan, B. R. (1978). One-Minute Medicine. Journal of the Amercian Medical Association, 257, 2798.

DeFoe, J. R., Breed, W., \& Breed, L. A. (1983). Drinking on television: A five year study. Journal of Drug Education, 13, 25-38.

Erickson, A. C., McKenna, J. W. , \& Romano, R. (1990). Past lessons and new uses if the mass media in reducing tabacco consumption. Public Health Reports, 105(3), 239-244.

Ferguson, G. A. (1981). Statistical analysis in psychology and education. New York: MCGraw-Hill Book Company.

Glynn, T. J. (1981). From family to peer: A review of the transitions of influence among drug-using youth. Journal of Youth and Adolescence, 10 (5), 363-383.

Haaken, J. H., \& Bowlden, L. (1991). Fighting the war on drugs. Against The Current, 19-26

Hareford, T. C., \& Mills, G.S. (1978). Age related trends in alcohol consumption. Journal of Studies on Alcohol, 29, 207-210. 
Herzog, A. R., Bachman, J. G., Johnston, L. D., \& O'Malley, P. M. (1987). Sex differences in adolescents' health threatening behaviors: What accounts for them? University of Michigan. Institute for Social Research, Monitoring the Future Occasional Paper, 23, December 1987.

Higgins, P. C., Albrecht, G. L., \& Albrecht, M. H. (1977). Black-White adolecent drinking: The myth and the reality. Social Problems, 25, 215-224.

Hopkins, R. H., Mauss, A. L., Kearney, K. A., \& Weisheit, R. A. (1988). Comprehensive evaluation of a model alcohol education curriculum. Journal of studies on Alcohol, 49(1), 38-50.

Johnston, L. D., \& O'Malley, P. M. (1986). Why do the nation's students use drugs and alcohol? Self reported reasons from nine national surveys. Journal of Drug Issues, 26(1), 29-66.

Kandel, D. B. (1980). Drug and drinking behavior among youth. Annual Review of Sociology, 6, 235-285.

Kelly, S. D. (1990). "Just Say No" is not enough. Virgina Journal of Education, 83 (June), 6-10.

Labouvie, E. W., Pandina, R. J., \& Johnson, V. (1991) Developmental trajectories of substance use in adolescence: Differences and predictors. International Journal of Behavioral Development, $14(3), 305-328$.

Mirzaee, E., Kingery, P. M., \& Pruitt, B. E. (1991). Sources of drug information among adolescent students. Journal of Drug Education, 21 (2), 95-106.

Moskowitz, J. M. (1989). The primary prevention of alcohol problems: A critical reveiw of the literature. Journal of Studies on Alcohol, 50(1), 54-86.

Newcomb, M. D., \& Bentler, P. M. (1985). Substance use and ethnicity: Differential impact of peer and adult models. The Journal of Psychology, 120(1), 83-95.

Oei, T. P. S., \& Baldwin, R. A. (1992). Smoking education and prevention: A developmental model. Journal of Drug Education, 22(2), 155-181.

Oetting, E. R., \& Beauvais, F. (1987). Common elements in youth drug abuse: Peer clusters and other psychosocial factors. Journal of Drug Issues, 2, 133-150.

Pascale, P. J., \& Evans, W. J. (1993). Gender differences and similarities in patterns of drug use and attitudes of High School students. Journal of Drug Education, 23, 105-116. 
Pisano, S., \& Rooney, J. F. (1988). Children's changing attitudes regarding alcohol: A cross sectional study. Journal of Drug Education, 18, 1-11

Pruitt, B. E., Kingery, P. M., Mirzaee, E., Heuberger, G., \& Hurley, R. S. (1991). Peer influence and drug use among adolescents in rural areas. Journal of Drug Education, 21(1), 1-11.

Ried, D. L., Martinson, O. B., \& Weaver, L. C. (1987). Factors associated with the drug use of fifth through eigth grade students, Journal of Drug Education, 27(2), 149-161.

Tobler, N. S. (1986). Meta analysis of 143 adolescent drug prevention programs: Quantitative outcome results of program participants compared to a control or comparison group. Journal of Drug Issues, 16, 537-467.

Signorielli, N. (1987). Drinking, sex and violence on television: The cultural indicators perspective. Journal of Drug Education, 17(3), 245-260.

Sibereisen, R. K., \& Noack, P. (1988) On the constructive role of problem behavior in adolescence. In N. Bolger, A. Caspi, G. Downey, $\&$ M. Moorehouse (Eds.), Persons in context: Developmental Processes (pp. 152-180) Cambridge University Press.

Sutherland, E. and Cressey, D. 1970. Criminology, Lippincott, New York. 


\author{
Appendix A \\ Interview Schedule \\ YOUTH'S PERCEPTIONS OF SOCIAL AND CULTURAL \\ DIMENSIONS OF DRUG USE
}

\title{
I. INTRODUCTION
}

There have been many books and articles written about drugs and the drug problems and how they affect kids, but no one has talked to kids about their own views and thoughts about drugs in this country. I am part of a group at Portland State University that is interested in finding out more about what young people think about drugs. We will talk for 45 to 50 minutes and I will be tape recording what we say. Everything that you say will be private and you are free to stop at any time. When we write a paper about these talks with students, there are no names included. This isn't a test -- there are no right or wrong answers to these questions. We are interested in your ideas. People have different opinions so feel free to share yours. Just pretend that I am from Mars and I don't know much about drugs and the concerns that some people have with them. I want you to give me the real scoop about drugs from your point of view.

Okay, first I will read you a couple of stories and ask you to comment on them. 
II. EXPLORATORY QUESTIONS

\section{A. General Conceptions of Drug Use}

1. Do you think there is a drug problem in your community or the country? If so, what kind? How much? (If you were to give a number from 1 to 10 with 1 being no problem and 10 being a very big problem, what number would you give to the drug problem in your community? In the country? Does that mean that most people are affected by it or take drugs? Or a problem in society?)

2. Why do you think people take drugs?

\section{B. Drugs and Society}

3. Are certain people or groups of people shown on TV or the movies to take drugs more than others? (Do you think that how they are shown is really true? Why do you think they are shown this way?)

4. What do you think about the anti-drug commercials that tell kids not to use drugs? Do you think the way drugs are presented on commercials is true? 
5. When you hear famous people, teachers, or other grown-ups say things like "Just say no to drugs", what do you think about that? what do your friends think about that?

\section{Parental and peer Relations}

6. Are there ways that you think about drugs that are different from the way your parents or other adults think about them? (Do you feel comfortable talking to or asking questions of your parents about drugs?)

7. Do you think people start using drugs because of what their friends want them to do? (What makes it cool to use drugs?)

8. Are drugs more important in some kinds of groups than others?

9. Is using drugs, or not using drugs, part of making or keeping friends? Do you have any idea why some kids join the groups that use drugs? (Rebellious groups)?

10. Are there any differences in how much boys and girls use drugs? Do the boys and girls that use drugs use for different reasons? (Are girls or boys more apt to have a drug problem?)

11. Do you think that rich kids and poor kids take drugs for different reasons? 
12. In what ways do you think kids that use drugs might help each other learn about drugs to make them safer? (Do kids who use illegal drugs ever try to help each other learn about the drug and how to use it in a safe way? Can you give examples?)

13. How do you think the kids in your school feel about kids who use drugs? Do you agree with that?

14. How do you think the kids in your school who use drugs feel about the kids who don't use drugs?

15. Do you think something about teenagers' lives leads to drug problems for some? Does the way that school or community is run contribute to drug problems?

16. If you were going to choose three important changes that could happen to deal with drugs in your community or the country, what would they be?

There are a few questions I would like to ask that are usually included in this type of study. 
III. DEMOGRAPHIC QUESTIONS

A. What is your birth date?

B. How many people live with you in your house?

C. What kind of work do your parents or the adults in your house do?

1). What type of work?

2). Are they self-employed?

3). Are they in management or in charge of other people?

Do you have any questions or have anything else you would like to say? (Are there questions that I haven't asked that you would like to include?) 
I, hereby agree to serve as a participant in the research project entitled "Youth's Perceptions of Social and Cultural Dimensions of Drug Use" under the supervision of Dr. Janice Haaken of Portland State University.

I understand that the study generally involves participation in a fifty minute audio tape recorded interview which will take place during one class time in a private room in my school.

I understand that generally interviews of this kind can be a positive experience, although some people may experience feelings of discomfort about discussing their thoughts or feel inconvenienced by missing class time.

It has been explained to me that the purpose of the study is to learn how young people understand and think about drug use and drug abuse. I also understand that the interview will not include questions about my own personal experiences of drug use nor of people that I know. I may not receive any direct benefit from participation in this study, but my participation may help increase knowledge which may benefit others in the future.

Dr. Janice Haaken has offered to answer any questions or concerns that I may have about the study, either before or after my participation. I have been assured that all information that I give will be kept confidential and neither my name nor identity will be used for any written paper or public discussion that results from this study.

I understand that I am free to withdraw from participation in this study at any time. I also understand that refusal to participate will not negatively affect my relationship with my teacher nor will my comments be shared with anyone but the research team.

I have red and understand this form and agree to participate in this study.

Student Signature Date

Parent Signature Date

If you experience problems that are the result of your participation in this study, please contact the Chair of the Human Subjects Review Committee, Office of Grants and Contracts, 303 Cramer Hall, Portland State University. 
Appendix C

CODE BOOK

Table of contents

Page

1. Introduction 73

2. Etiology of drug use 73

3. Country and community problems 74

4. Media coverage 75

5. "Just Say No" campaign 78

6. Parent / child relations 78

7. Group drug use 79

8. Gender differences in drug use and culture 79

9. Socio-Economic status and drug use 80

10. Forms of helping within drug using groups 81

11. User / non-user relations 82

12. Family structure 83

13. Socio-economic status of participants 83 
CODE

\section{Instructions :}

Code each theme as it occurs in each response unit. Each response unit is defined as a statement following each question by an interviewer whether the question is a primary question or a probe question. If a respondent simply repeats or reaffirms the previous statement, do not recode, i.e. responding to the interviewers paraphrase.

\section{ETIOLOGY OF USE}

1. Social reasons

A. Peer approval or disapproval

PEER-GR Desire for peer group conformity/group identity. Individual gets something from the peer group through use (emphasis on belonging or merger with group identity). Fear of peer group sanctions or disapproval, being seen as stupid or nerdy or being seen as not tough or weak. Also to achieve admiration or recognition from peers, e.g. being seen as cool or tough. Emphasis on differentiation from others, reputation among peers. (If focus on drugs as a vehicle or basis of group life, see GROUP codes).

- because a best friend is really popular and does drugs and you want to be popular also

- especially if you go to parties and there is stuff there, then they expect you to do it too

PEER-DY Drug use to maintain a friendship or relationship with another person / dyadic relationship through sharing common activities.

(If the friendship is described in general terms, without specific mention of a dyadic relationship, then code PEER-GR) .

B. Relationships with authority

AUTH-R Using as Rebellion against authority or response to conflictual engagement with authority, e.g. defying adult constraints on behavior, engaging in tabooed behavior or getting attention in a negative way.

- people just want to rebel or be against society and using drugs is an easy way to do it, it's not something that's legal

- some kids use drugs just to get noticed by their parents 
AUTH-M Using based on adult modeling, or learning from watching parents or other adults or wanting to be more like adults; drugs as a rite of passage.

- if their Mom and Dad are using them, they may think that it's ok to use as well

- it makes you feel more grown-up

- if you use drugs you feel older, then no one can push you around

\section{Experimentation}

EXP Curiosity about a novel or new experience, openness to risky situations. True knowledge requires direct experience.

- they're just curious to see what it's all about

- to see what it feels like to actually experiment with them

- you have to find out what's true for yourself

3. Pharmacological effect (physical/emotional)

PHARM-PLEAS Seeking pleasurable stimulation or sensations, i.e. physical pleasure, excitement, fun stimulation.

(if mention is made of getting away from any sort of problems or pressures, code PHARM-ESC)

- to get high

PHARM-OVER Overcoming constraints, permits the overcoming of constraints by creating a pleasurable state, i.e., overcoming inhibitions, loosening up, increasing sociability.

PHARM-ESC Escape from problems, drugs provide a means of escaping problems in living, painful experiences, i.e. pressures or stress from family, friends, boredom (depression, passivity) problems imposed by external demands.

- they may take them to make themselves feel better

- some people just do it because they feel there's nothing else to do

- to relax and unwind, to get away from the whole world, not to hide from it, just to get away from it for awhile

\section{COUNTRY AND COMMUNITY PROBLEMS}

PROB-EXT Country or community problems are seen to be caused or worsened by the flow of drugs from external sources. Any mention of outside influences or drug traffic should be coded here. May also include ideas that drug problems only occur in large cities or in other places.

- I hear they sneak most of the drugs in from Panama

- I think it's worse in other cities, bigger cities with more problems 
PROB-GOV The government is seen as the reason for many of the problems related to drug use and abuse, either allowing it to occur or in some way exacerbating the problem.

- it's the government's fault, they want to keep drugs available

- many high up government officials have drug problems so other people think they an use them too

- drugs are the downfall of the USA, they are spreading like crazy and it's coming down from the top dogs

- government isn't clamping down enough on drug traffic

PROB-DRUG-CAUSE Drugs and drug use are viewed as a primary cause of problems in either the community or country and pose a threat to society. Drugs are seen as the cause of sadness, illness, poverty, prostitution, and even death. May also include economic costs of drug use or gang related violence.

- you see a lot of stealing and vandalism to get drugs

- there's a lot of drug selling, even to young kids

- people just messing themselves and their families up by using drugs

- there's a big problem with drinking and driving

\section{MEDIA COVERAGE}

Includes TV., movies, radio, print media, comics and books. Begin with the question "Are there certain people or groups of people that are shown to use drugs more than others."

\section{Characteristics of drug users in the media}

Drug users or dealers are portrayed in the media as belonging to particular social groups. Persistent stereotypic display of particular groups in the media. (Also code SCAPE if an inference is made about particular groups being portrayed as the source or cause of drug problems in society. Also see section 3 of anti-drug commercials).

MEDIA Persistent stereotypic display of particular groups in the, media. **NOTE: all categories have been collapsed into this one except the following two.

- the movies really play up certain images of users

- there are some movies you see that show mostly young people on the streets using it a lot

- they may show a good student that uses drugs and then slowly fades away

- on TV they'll show a big guy with a curl that's the drug user

MEDIA-C color or non-white, e.g. dark skinned, people of color, Blacks, Latinos, Asians, Native Americans.

- it seems that when I look at TV they are portraying blacks

MEDIA-LOW POor or lower class, including homeless, e.g. poorer people, low-income, working class people. Suggests a broad economic category.

- most of the movies show people that live pretty low class 
- the people from the slums are mostly shown

2. Accuracy / Distortions in media portrayals of drug use or users

MED-ACC General statement that the media accurately portrays various groups. Drug users are accurately portrayed in the media as belonging to a particular social group. Includes responses where the media portrayal is seen as partly true or to some extent true. (If mention is made of distortions, also code MED-DIS).

MED-DIS The way drugs or drug use is shown is distorted. Drug use is glamorized, portraying famous people or high society using drugs or vilified, portraying lower class people as more taken over by drugs. Media may show what mostly happens, but it is exaggerated in the portrayal of people who use.

MED-DIS-I Some distortion in how information about drugs or drug use is presented, either through misinformation or concealing information. Focus on distortions in properties of drugs or consequences of use, or inaccurate information. May also include under-informing in some way.

- they say marijuana is worse, but I've read that it's not as bad as cigarettes

3. Drug users or dealers are scapegoated.

Social attention is focused on particular groups as users or dealers in order to divert attention from either use among other groups or larger social issues. (Refers to any scapegoating of drug users, including in the government, media, schools, or society).

SCAPE-LOW The lower class, poor, homeless or marginal are the focus of anti-drug policy or to focus blame. May include the idea that this distracts from use among the wealthy.

SCAPE-COLOR The blame is placed on people of color. (If male gender is mentioned, code SCAPE-COLOR-M).

- even though they do commit some crimes, I feel minorities are scapegoated for everything

- government uses people of color to base and aim policy

- the blacks, they are the fall guys and often get the blame from the government

4. Critical and positive aspects of Anti-drug commercials

(Code only for "What do you think about the anti-drug commercials that tell people not to use drugs.")

A. Critical Responses.

COMM-HYP Actors used in the commercials are hypocrites, e.g., may actually use or have used or the actors don't really care, they are just getting paid to do it. 
- he did the commercial and later it came out that he uses cocaine

- Arnold did a commercial on not using drugs, but I remember a scene when he was passing around a joint

- he's probably going to get off the set and drink a beer

COMM-DIS A false or distorted portrayal of reality, they don't show how drugs really affect people. May include a tendency to minimize dangers involved; lack portrayal of pleasures along with the dangers; only focus on a limited number of drugs or only focus on or target certain groups. Omission of certain facts about drugs.

- they're corny, poorly done, it's not like real life

- commercials just sort of make a general statement saying what illegal drugs are, but they're not saying what they really are

COMM-PROP Serve as propaganda, i.e. use of scare tactics or emotional messages, moralism, fear. Once you use you are over the line (no redemption). Implies motivation behind distortion in commercials or creating emotionally charged anti-drug messages or excessive fear of drugs.

- they try to make it look like there's this bad Mr. Drug Lord that is all powerful and that one puff of marijuana would turn you into a junkie overnight

- some of these commercials make it look like people are insane and that they want to kill everyone to get the drug

COMM-INEFF Commercials are ineffective, condescending, or not informative, the level is too low, .e.g. the message is only appropriate to younger kids, they don't allow for the formation of independent opinions or they are not technical or informative enough. May also be overdone, or inundate children with these messages (they no longer have meaning).

- everyone I know makes jokes about them, they think we are idiots

- it's kind of bad that they're not letting you make your own decision

- some are so short and say so little that it doesn't really say anything

- the commercials cram it down our throats

- useless, we've heard it all too many times

B. Positive responses (Includes a positive view either of existing or potential use of commercials).

COMM-POS-MOD Portray positive models that can be followed, the actor has influence or power that can be followed, the actor has influence or power that is helpful to kids in promoting anti-drug messages.

- they should use those comic strip heroes, kids might listen to them

COMM-POS-GOOD Commercial is good or well done, some can be informative or helpful in some way. 
- the commercial using the frying eggs has a strong message

- some tell the parents to get off of them so the children won't do it

- one commercial shows the different kinds of drugs and says you shouldn't do it

\section{"JUST SAY NO" CAMPAIGN}

Famous people/teachers saying "just say no" to drugs or "just say no" campaign. (Begin with the question, "When you hear famous people or teachers say "just say no", what do you think?)

JUST-POS Campaign is positive or useful and help remind kids that drugs are bad. Saying "just say no" is good, it helps remind us that drugs are harmful.

- because if my teacher says not to use drugs, then I really shouldn't

- when people you know like Barbara Bush or Nancy Reagan, then it's pretty good

JUST-CRIT Some critical feelings towards the "just say no" campaign.

- I don't think there is any point, it doesn't do any good

- after awhile it loses its effect, many kids will just tune it out

- it all seems like a big publicity campaign

JUST-AMB Not sure about the usefulness or have some ambivalence regarding some part of the campaign.

- the program is ok, but it should have a message for adults, not just for kids

- only helpful to younger kids, but not for kids my age

\section{PARENT/CHILD RELATIONSHIPS}

1. Parental or significant others views on drugs.

Rate parental views from strong positive to strong negative if possible $1=$ pro drug, $3=$ neutral, $5=$ strong anti-drug.

Record subjects' rating of comfort with parents

If possible, put a number in the margin for each parent.

2. Similarity of parental or parental surrogate (e.g. stepparent or other adult who serves as a parent) and child's views.

SIM-PAR Have similar views as one or both parents.

- I can talk to them, they don't take drugs and I don't either

- I believe we think the same, by talking, they help me learn about drugs and not to use them (also code DISCUSS-YES) 
DISSIM-PAR Have dissimilar views as one or both parents

- My parents and I don't have the same ideas, their views are too outdated.

DISCUSS-YES Able to discuss views on drugs with one or both parents.

- my parents talk to me and tell me the dangers of drugs

DISCUSS-NO Not able to discuss views on drugs with one parent or the other.

- I believe we think the same, but I don't talk with them (also code SIM-PAR)

- I think we have the same feelings about it, but I can't talk to my parents because they want to hide you from it

\section{GROUP DRUG USE}

(Description of the group experience or the quality of group life facilitated by drug use).

GROUP-SIT Use is situationally defined by association in a common meeting place or activity. Description of specific setting. Use is situational to proximity, place or specific activity.

- they have a place in an old building where they all get together

- party together - have fun and do drugs

- heavy metal rockers - common identity

- brought together in a club or meeting place

GROUP-IDENT Drug use as part of the group identity or culture. Use based on or creates a group culture or is central to group culture. Gang drug use as part of their culture.

- drugs used as a recruiting incentive

- sale of drugs for financial support of gang

- some cultures use the drugs as part of their religion

- cultural heritage of the group (Indians)

- heavy metal rockers - common identity

\section{GENDER DIFFERENCES IN DRUG USE AND CULTURE}

GEND-NO No differences in amount or reasons for use. May mention individual differences, but not viewed as related to gender.

- some boys use more than some girls and some girls use more than some guys

- I haven't seen any real differences in use

GEND-YES There are differences in the amount or reasons for use between girls and boys, but no clarification is given.

1. BOY- Boys use more, use differently or for different reasons. 
- mostiy just boys use drugs

BOY-IDEAL Drugs are used to realize masculine ideals. Drugs facilitate masculine feelings or ideals, e.g. of sexy, a stud, tough, adventurous, or strong. May also include rebellion or risk taking. Includes masculine ideal of athletic prowess or strength (e.g. steroid use).

- it's macho to use, maybe they feel holding a bottle of beer in their hand is macho

- using makes you feel like you're tough, able to be one of the group or guys

- he might take them to be cool and to keep his friends (Implies masculine context)

- sports are competitive, so they use steroids to build themselves up

BOY-PROB Masculine problems lead to increased use. Males are more likely to have problems with competition, relationship that lead to the use of drugs as a means of dealing with problem (understood to be some kind of a problem).

- guys have trouble feeling like they can be on top of things

- boys are always trying to get away from their families/hassies

- males might try to escape, they have more problems in their lives

2. GIRL- Girls use more, use differently, or for different reasons.

GIRL-PROB Feminine problems (self-perceived) lead to increased use. Females are more likely to have emotional problems, or to be emotional or to have social pressures that lead to use. Includes the idea that girls are more apt to conceal drug problems.

GIRL-IDEAL Girls are more likely to conform feminine ideals. Girls are more likely to use to be part of the group or connect with others or to please or attract boys. May also strive for social stereotypes of thinness and attractiveness.

- she likes a popular guy and uses to impress him

SOCIO-ECONOMIC STATUS AND DRUG USE

1. No real differences in use.

SES-ND No real differences in use. Drug use and general patterns of use are similar. 
- both groups can get them if they want them, it doesn't matter if they're rich or poor

- both use to get away from their problems although they may have different problems

2. Upper class or wealthy use more or differently.

UP-MORE Upper class or rich use more or use differently. May use performance enhancing drugs or use drugs to gain status.

- rich kids do it more, they can afford it

- rich people are more likely to use

- rich kids have less responsibilities and more leisure time, so they are more prone to use drugs to amuse the themselves

- I think they use more expensive drugs like cocaine or others

- their drugs are more serious, a big majority have drug problems, maybe because their drugs are more expensive or more effective

3. Lower class use more or differently.

LOW-MORE POOr or lower class use more drugs of differently. Lower class use more to escape from problems or difficulties in their lives. Poor have more deviant role models.

- poor people may use and produce more drugs

- poor people use drugs to make more money

- people in poverty have access to them, but they would rather spend money on food and other things

LOW-DEAL Poor or lower classes are more into dealing.

- rich use more, the poor sell more

- the poor sell more because the need the money

FORMS OF HELPING WITHIN DRUG USING GROUPS

DRUG-GRP-INFO Provision of economic aid or information about drugs or their use within the group. Inform others of the appropriate amount, share knowledge about the affects of the drug or how to use the drug or warn them regarding the potential dangers of use. Inform others of places to go to get drugs or groups that use.

- They might help each other to get drugs

- there is some teaching that goes on, they tell each other not to use too much or how much to use to get the desired affect.

- members of groups might sell drugs to each other

- they might loan them money to buy some drugs

DRUG-GRP-SUPP Provide the motivation or support for experimentation and ongoing use. May motivate them to experiment 
with some new or exciting drug or take them to parties at which drug use occurs. This support may also include covering up for each other.

- they might cover up for the other person: tell their parents that they are at the other person house

- $\quad$ someone may something like "hey, do you want to try a new drug with us."

DRG-GRP-STOP The group may provide encouragement to stop using. The group may encourage the user to get involved in a program or seek out some counseling to help them stop. If one of the group wants to stop using, allowing them to do so with hindrance. May involve informing the parents or other adults and try to get them to help them or get other non-users involved.

- one could take someone from his group to the doctor to help him quit

- if you want to quit "it's cool", or go to a place where there aren't too many people using

\section{USING/NON-USING GROUP RELATIONS}

1. Feelings of non-users towards users

USER-ND General response- they seem to get along just fine; no real differences in the way they treat each other.

- it mostly depends on the people involved, not necessarily if they use drugs or not

USER-DUMB People that use drugs are dumb or stupid because they know that drugs are bad but still want to use them. Include any statement of ridicule.

- they are scum or low lives because they use

- they are really making bad choices using drugs

just for fun or because somebody tells them to

USER-FEAR Non-user feels some fear and wants to maintain some distance (physical or emotional) from the users.

- we stay way from them, we call them names and make fun of them

USER-PROB They use because of some problem in their life that leads them to use drugs or the cause of their problem. Includes statements regarding their personalities, position in life or school problems.

- I think they just don't care about themselves, let them screw up their lives

- most of the guys in the group have problems, and I tend to stay away from those guys 
USER-KIND Some expression of kindness, friendliness or remorse for the user. Code here any statement that indicates they think they are ok or cool people. Also include statements or ideas of wanting to help get the user off drugs.

- kids that use are grown up because they have experienced drugs.

- I just feel sorry for them and want to help them stop

- some look up to the users or dealers because they are rich

\section{Feelings of users towards non-users}

NON-USER-UNCOOL Users think people that haven't used are uncool because they haven't had the experience of using drugs. Include here any derogatory statements about the non-users.

- they think they are really straight or nerds

- they would consider them to be naive and have small social scope

NON-USER-BETTER NOn-users are better or lucky because they don't have all the problems to deal with including drug use. Include here any ideas that the user might want them for a friend or want to aid in stopping the use of drugs.

- they might want them for a friend so they can help them to get off drugs

- users may think non-users are too good for them

\section{FAMILY STRUCTURE}

Code the number of people in the family in the margin

Note the family structure in the margin; list Father, Mother, parental surrogate or other type of arrangement. You may refer to the section on communicating with parents.)

\section{SOCIO-ECONOMIC STATUS}

Choose only one of the following codes for the family

SES-UNSTAB Includes any family that the caretaker ie either unemployed or works only on an unstable basis.

SES-WORKING Includes any family that the worker has to sell their labor in order to generate an income. Includes skilled as well $\mathrm{s}$ unskilled laborers. May include people that have some control over their job, but are still dependent on the boss for work. 
- teacher, machine shop, technician, clerks, engineers, musicians SES-MAN-PROFF Includes all those in the upper management or professional positions in which they have autonomy or control. Must be more than a lower level supervisor. May also include business owners that run their own business. May also include doctors, lawyers or engineers that manage their own clinics or firms.

- PGE vice president, partner in a law firm 
Appendix D

$$
\begin{gathered}
\text { Number of transcripts in } \\
\text { which code appears } \\
\text { by group }(n=32)
\end{gathered}
$$

$\begin{array}{lllllll}\text { Code } & \text { AA } & \text { C } & \text { M } & \text { F } & \text { 4th } & 11 \text { th } \\ \text { Auth-Mod } & 18 & 13 & 12 & 19 & 19 & 12 \\ \text { Boy-Prob } & 10 & 14 & 12 & 12 & 7 & 17 \\ \text { Comm-Dis } & 5 & 7 & 9 & 3 & 5 & 7 \\ \text { Comm-HYp } & 3 & 7 & 5 & 5 & 1 & 9 \\ \text { Comm-Ineffect } & 11 & 13 & 11 & 13 & 6 & 18 \\ \text { Comm-Pos-Good } & 26 & 25 & 24 & 27 & 30 & 21 \\ \text { Experiment } & 15 & 15 & 16 & 14 & 11 & 19 \\ \text { Gend-No } & 26 & 19 & 18 & 27 & 22 & 23 \\ \text { Just-Crit } & 17 & 13 & 16 & 14 & 7 & 23 \\ \text { Just-Pos } & 16 & 18 & 17 & 17 & 24 & 10 \\ \text { Low-More } & 25 & 19 & 21 & 22 & 16 & 27 \\ \text { Peer-Group } & -- & -- & --a 11 & - & -- & -- \\ \text { Pharm-Esc } & 26 & 30 & 28 & 28 & 29 & 32 \\ \text { Pharm-Over } & 1 & 6 & 5 & 2 & 1 & 6 \\ \text { Pharm-Plea } & 18 & 13 & 14 & 17 & 11 & 20 \\ \text { SES-ND } & 25 & 18 & 12 & 21 & 13 & 21 \\ \text { Up-More } & 25 & 19 & 20 & 23 & 16 & 28 \\ & & & & & & \end{array}$

Codes not used:

$\begin{array}{lllllll}\text { Auth-Reb } & 14 & 11 & 12 & 13 & 10 & 15 \\ \text { Boy } & 10 & 15 & 13 & 12 & 11 & 14 \\ \text { Comm-Pos-Model } & 2 & 6 & 6 & 2 & 4 & 4 \\ \text { Comm-Prop } & 1 & 3 & 3 & 1 & 0 & 4 \\ \text { Gend-Yes } & 9 & 9 & 12 & 6 & 11 & 7 \\ \text { Just-Amb } & 9 & 12 & 10 & 11 & 9 & 12 \\ \text { Media } & 21 & 25 & 25 & 21 & 18 & 28 \\ \text { Media-AcC } & 19 & 12 & 16 & 15 & 15 & 16 \\ \text { Media-Dis } & 20 & 20 & 20 & 20 & 15 & 25 \\ \text { Pro-Dr-Cau } & 12 & 12 & 10 & 14 & 8 & 16 \\ \text { Prob-External } & 11 & 13 & 17 & 7 & 9 & 15 \\ \text { Prob-Gov } & 6 & 6 & 8 & 4 & 2 & 10 \\ \text { Scape } & 9 & 8 & 9 & 8 & 1 & 16\end{array}$


Appendix E

Kappa Totals

Kappa totals for 3 separate sets of 12 transcripts

SET 1 (Transcript \#s) $24,21,22,9,52,61,602,18,19,20,47,58$

SET 2 (Transcript \#s) $8,99,15,46,45,43,40,28,14,12,5,4$

SET 3 (Transcript \#s) $42,29,57,56,35,25,63,33 b, 48,44,26,39$

Kappas for each set by thematic category

SOCIO ECONOMIC STATUS (SES) .84,.75,.65, (Average $=.75$ )

GENDER DIFFERENCES $.63, .65, .70$, (Average $=.66$ )

JUST SAY NO $.63, .57, .67$, (Average $=.62$ )

COMMERCIALS $\quad .71, .68, .63$, (Average $=.68$ )

ETIOLOGY $.76, .70, .70$, (Average $=.72$ ) 